\title{
La cerámica de Coscopunta, un sitio del Periodo Intermedio Tardío en la provincia de Carhuaz, Callejón de Huaylas, Perú
}

La céramique de Coscopunta, un site de l'Intermédiaire récent dans la province de Carhuaz, Callejón de Huaylas, Pérou

The Ceramics from Coscopunta, a Late Intermediate Period site in the province of Carhuaz, Callejon de Huaylas, Peru

Richard L. Burger y Lucy C. Salazar

\section{OpenEdition}

\section{Journals}

Edición electrónica

URL: http://journals.openedition.org/bifea/7377

DOI: 10.4000/bifea.7377

ISSN: 2076-5827

Editor

Institut Français d'Études Andines

Edición impresa

Fecha de publicación: 1 abril 2015

Paginación: 23-52

ISSN: 0303-7495

Referencia electrónica

Richard L. Burger y Lucy C. Salazar, « La cerámica de Coscopunta, un sitio del Periodo Intermedio Tardío en la provincia de Carhuaz, Callejón de Huaylas, Perú », Bulletin de l'Institut français d'études andines [En línea], 44 (1) | 2015, Publicado el 08 mayo 2015, consultado el 06 noviembre 2020. URL : http://journals.openedition.org/bifea/7377 ; DOl : https://doi.org/10.4000/bifea.7377

\section{(c) $(ஒ) \ominus$}

Les contenus du Bulletin de l'Institut français d'études andines sont mis à disposition selon les termes de la licence Creative Commons Attribution - Pas d'Utilisation Commerciale - Pas de Modification 4.0 International. 


\title{
La cerámica de Coscopunta, un sitio del Periodo Intermedio Tardío en la provincia de Carhuaz, Callejón de Huaylas, Perú
}

\author{
Richard L. Burger* \\ Lucy C. Salazar**
}

\begin{abstract}
Resumen
Este artículo ofrece la descripción de un gran grupo de vasijas completas o casi completas fechadas en el Periodo Intermedio Tardío que fueron descubiertas por un agricultor en 1979 en la aldea de Coscopunta, cerca del pueblo de Anta, provincia de Carhuaz, Ancash. Esta cerámica tiene un alto grado de variabilidad pero una baja calidad en su producción. Aunque este estilo comparte elementos con otros estilos de la misma época en la zona, como Aquilpo, Chakwas y Pójoc, es fácil distinguirlo. Esta observación refuerza la impresión de que en la sierra de Ancash, durante el Periodo Intermedio Tardío, se produjo cerámica local en muchos lugares y que esta cerámica no servía de vehículo para representar unidades políticas o étnicas. Al mismo tiempo, el análisis de la cerámica de Coscopunta ofrece evidencia para contactos directos entre las comunidades de la Cordillera Negra, e inclusive con grupos más al oeste en la costa norte. Finalmente, se plantea la hipótesis que el grupo de cerámica completa y otros materiales descritos en este ensayo podrían haber sido enterrados como ofrendas a un huanca ubicado en un campo de cultivo en Coscopunta.
\end{abstract}

Palabras claves: Periodo Intermedio Tardío, Callejón de Huaylas, Estilo Aquilpo, huancas

* Department of Anthropology, Yale University, 10 Sachem Street, New Haven, CT 06520-8277. E-mail: richard.burger@yale.edu

** Department of Anthropology, Yale University, 10 Sachem Street, New Haven, CT 06520-8277. E-mail: lucy.salazar@yale.edu 


\title{
La céramique de Coscopunta, un site de l'Intermédiaire récent dans la province de Carhuaz, Callejón de Huaylas, Pérou
}

\section{Résumé}

Cet article décrit un ensemble important de céramiques entières ou presque entières datant de I'Intermédaire Récent, découvertes en 1979 par un agriculteur dans le village de Coscopunta, près de Anta, province de Carhuaz, Ancash. Cette céramique est très variée, mais de facture médiocre. Bien que certains éléments de ce style soient comparables à d'autres styles de la même époque dans la région, comme Aquilpo, Chakwas y Pójoc, il est facile de les différentier. Cette observation renforce I'impression que dans la sierra de Ancash, au cours de l'Intermédiaire récent, de la céramique ait été produite localement dans de nombreux endroits et que cette céramique n'ait pas servi de véhicule de representation des unités politiques ou ethniques. En même temps, l'analyse de la céramique de Coscopunta permet de prouver l'existence de liens directs entre les communautés de la Cordillère noire, et même avec des groupes plus à l'ouest sur la côte nord. Finalement les auteurs proposent que l'ensemble des céramiques entières et d'autres matériels décrits dans cet article aient été entérrés comme offrande à un huanca situé dans une parcelle de culture à Coscopunta.

Mots-clés : Intermediate récent, Callejón de Huaylas, Style Aquilpo, huancas

\section{The Ceramics from Coscopunta, a Late Intermediate Period site in the province of Carhuaz, Callejon de Huaylas, Peru}

\begin{abstract}
This essay describes a large group of complete or nearly complete Late Intermediate Period pottery vessels uncovered by a farmer in 1979 at the site of Coscopunta, near the town of the Anta, Carhuaz Province, Ancash. The assemblage, consisting mainly of jars and bowls, shows a considerable diversity in its style and low quality in its production. While the pottery style shares features known previously from the Callejón de Huaylas and Conchucos, it is easily destinguishable from these other styles (e.g. Aquilpo, Chakwas, Pójoc). This reinforces the impression that ceramics during the Late Intermediate Period were locally produced in the northern highlands and did not serve as emblems of large political or ethnic units. At the same time, the ceramic assemblage from Coscopunta offers evidence of direct contact between different communities in the Cordillera Negra, as well as with groups living on the Pacific coast. Finally, it is hypothesized that the group of pottery and other materials discussed in this article may have been deposited as offerings to a huanca located in the middle of an agricultural field at Coscopunta.
\end{abstract}

Keywords: Late Intermediate Period, Callejon de Huaylas, Aquilpo Style, huancas

\section{INTRODUCCIÓN}

Los estilos de cerámica han jugado un rol central en la arqueología andina a lo largo de mucho tiempo y, aunque los enfoques basados exclusivamente en la cerámica no caracterizan más los trabajos de campo, los investigadores siguen reconociendo su importancia crítica en la discusión de la interacción local, regional y panregional, así como en la cronología relativa e identidad local. Muchos estilos 
de cerámica del Periodo Intermedio Tardío, tales como Chimú o Chancay, son conocidos por más de un siglo, pero otros todavía permanecen sin ser descritos en la literatura profesional.

La mayor parte de los estilos cerámicos en la sierra que datan del Periodo Intermedio Tardío, incluyendo aquellos del departamento de Ancash, corresponden al último grupo. En el caso de la sierra de Ancash se pueden identificar tres razones que explicarían esta situación: 1) han sido excavados pocos sitios del Periodo Intermedio Tardío; 2) los sitios del Periodo Intermedio Tardío que han sido excavados muestran una ausencia de entierros intactos y, por lo tanto, contienen pocos ejemplares de cerámica entera; y, 3) la cerámica del Periodo Intermedio Tardío de la sierra de Ancash es poco atractiva para los investigadores modernos. Como consecuencia de los factores anteriormente señalados, se ha publicado muy poco sobre vasijas completas del Callejón de Huaylas que datan del Periodo Intermedio Tardío. Aspecto desafortunado, ya que en el esfuerzo por definir o caracterizar un estilo de cerámica desconocido es útil tener disponible una muestra de vasijas completas o casi completas, a fin de entender mejor sus proporciones y la manera cómo el acabado y la decoración se integran en la morfología de la vasija. Mientras que en la mayoría de las excavaciones puede obtenerse algo de información sobre los tiestos recuperados, estudios de lo último se benefician de publicaciones complementarias de vasijas enteras.

La primera definición de un estilo cerámico del Periodo Intermedio Tardío de la sierra de Ancash fue propuesta por Gary Vescelius y Hernán Amat hace más de cuatro décadas, sobre la base de fragmentos de cerámica recuperados durante sus trabajos en las localidades de Maracará y Carhuaz en la parte central del Callejón de Huaylas (Buse, 1965; Lanning, 1965). Vescelius y Amat lo llamaron estilo Aquilpo y este término aparece frecuentemente en la literatura arqueológica.

Desafortunadamente, el conjunto de cerámica Aquilpo nunca fue descrito en detalle ni se publicaron ilustraciones o dibujos de los materiales. Posteriores investigaciones en el Callejón de Huaylas por parte de Steven Wegner, Francisco Bazán, Victor Ponte, George Lau y otros han producido cerámica del Intermedio Tardío y, aunque este material ha sido descrito en informes oficiales — con pocas excepciones (p. ej. Bazán, 2011; Lau, 2010)_ aparece poco en la literatura publicada.

Un patrón de abandono similar caracteriza a los estilos cerámicos relacionados del vecino Callejón de Conchucos, localizado al este de la Cordillera Blanca. Richard Burger ofreció una descripción de cerámica excavada datada del Periodo Intermedio Tardío de las tierras agrícolas altas, por encima de Chavín de Huántar, en la cuenca del río Mosna. Esta cerámica de los sitios de Pójoc y Waman Wain fue referida al estilo Pójoc y fue descrita e ilustrada brevemente en un reporte sobre dichas excavaciones (Burger, 1982). Sin embargo, este trabajo se enfocó, principalmente, en la ocupación del Horizonte Temprano en estos dos sitios.

Aquí se presenta la descripción y discusión de un grupo de 21 vasijas completas - o casi completas - del Periodo Intermedio Tardío procedentes del sitio de 
Coscopunta. Esta colección fue documentada durante nuestro trabajo de campo en el sitio de Huaricoto (Marcará), en 1979 y 1980. A pesar de que la información arqueológica concerniente a estos especímenes es limitada, se cree que la colección de Coscopunta aún puede proporcionar conocimientos sobre los estilos de cerámica del Periodo Intermedio Tardío en el Callejón de Huaylas.

\section{ORIGEN DE LA COLECCIÓN}

Antes de la descripción e ilustración de las vasijas se justifica una breve discusión de su proveniencia. El 2 de febrero de 1979, durante la temporada de campo en el sitio arqueológico de Huaricoto, se acercó el señor Alejandro Eugenio Moreno, un agricultor de la comunidad de Coscopunta ubicada en la Cordillera Negra (distrito de Anta, provincia de Carhuaz), quien nos mostró un lote de vasijas que había recuperado mientras preparaba sus parcelas para la siembra (fig. 1). Indicó que las vasijas de cerámica que traía no procedían de una chullpa o tumba subterránea sino del arado de su chacra. Al mismo tiempo, fue reticente a llevarnos a Coscopunta debido a la oposición de la comunidad frente a los visitantes y al temor de que el descubrimiento de los «huacos» condujera a la expropiación de sus tierras por parte del gobierno nacional. No obstante, creía que los objetos arqueológicos eran de importancia y que debía entregarlos a especialistas para asegurar su preservación. Luego de preguntarle más ampliamente, indicó que materiales arqueológicos adicionales habían sido recuperados en su chacra en Coscopunta y acordó llevarlos, en una fecha posterior, al Museo Arqueológico de Ancash, en Huaraz. Un mes más tarde cumplió su promesa.

La colección de artefactos de Coscopunta no fue solicitada por nosotros y no se pagó por ella. Estamos convencidos de la veracidad del lugar de proveniencia y las otras informaciones voluntariamente proporcionadas respecto a los materiales arqueológicos de Coscopunta. Todas las vasijas de Coscopunta fueron posteriormente entregadas por los autores a Odón Rosales Huatuco, en ese momento director del Museo Arqueológico de Ancash en Huaraz, pasando a formar parte de su colección permanente.

El señor Moreno describió Coscopunta como una aldea en la cima de una colina localizada a dos horas y media a pie del pueblo de Anta, sobre la orilla oeste del río Santa. Nos indicó que era necesaria la aprobación previa de la comunidad para visitar el pequeño poblado. Nuestra participación en los trabajos de campo en Huaricoto no estuvo relacionada con la arqueología del Periodo Intermedio Tardío. Además, nuestro trabajo en el Callejón de Huaylas fue abruptamente interrumpido por la violencia producida por Sendero Luminoso. En consecuencia, no pudimos visitar Coscopunta y no conversamos con el agricultor nuevamente.

La colección de 21 vasijas recuperadas de Coscopunta en 1979 no muestra evidencia de elementos estilísticos Inca y basados en la evidencia de la similitud general de la cerámica a los estilos Aquilpo, Chakwas y Pójoc de la sierra de Ancash, así como con el estilo Casma de la costa (Pozorski \& Pozorski, 2012; 


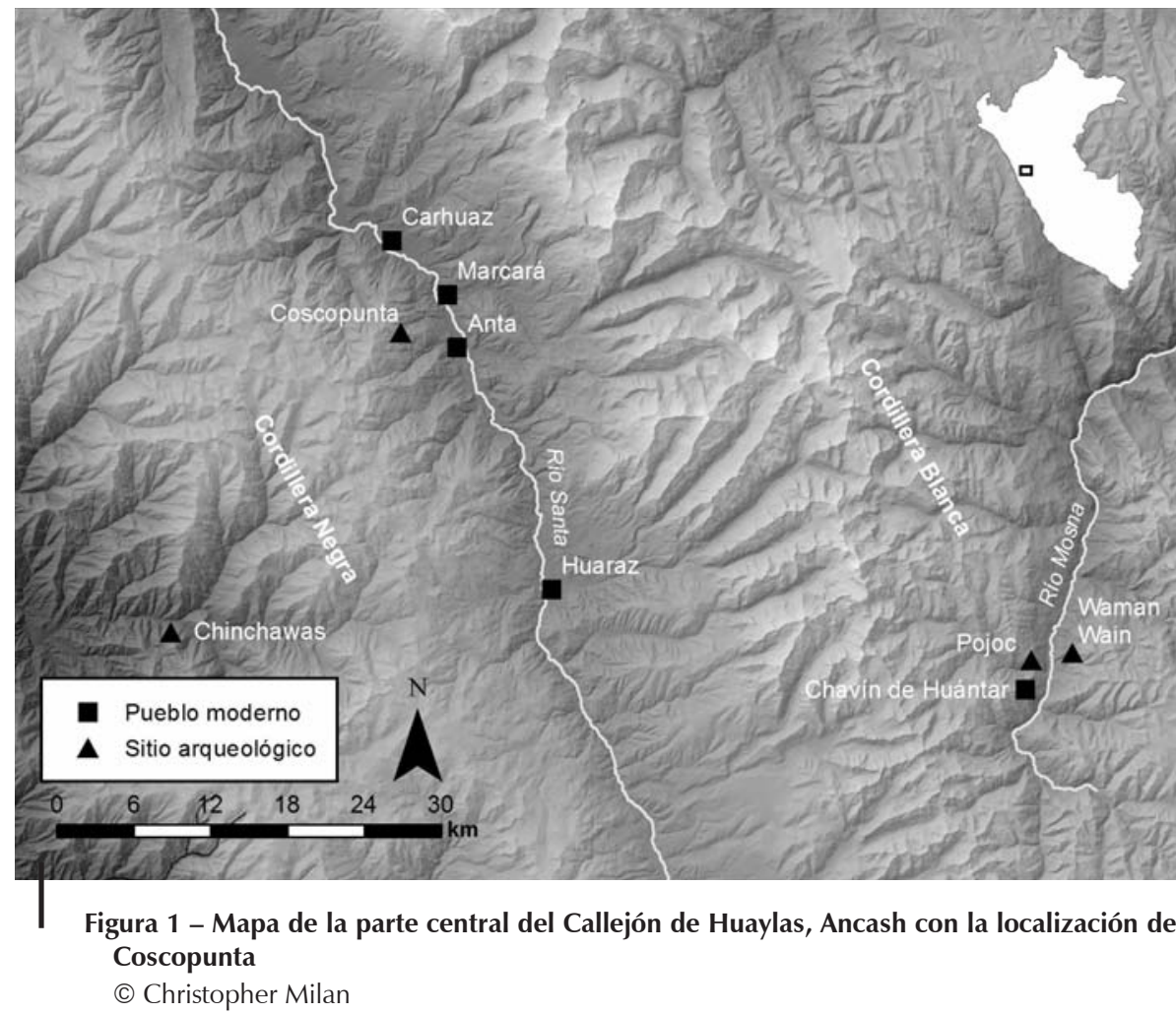

Vogel, 2011), interpretamos que toda esta colección data del Periodo Intermedio Tardío. Esta conclusión es consistente con la identificación de una de las piezas encontrada en Coscopunta como una vasija importada de la costa norte en el estilo Sican Tardío.

La mayor parte de la colección de Coscopunta consiste en vasijas completas o casi completas e, incluso, los especímenes fragmentados parecen provenir de vasijas rotas durante su extracción del suelo. A pesar de no ser completamente homogéneas, la mayoría de las piezas parecen haber sido producidas en un solo estilo local relacionado - pero no idéntico - a los estilos previamente descritos para la sierra de Ancash.

Adicionalmente a las vasijas traídas desde Coscopunta por el señor Moreno, la colección del sitio también incluye otros cuatro artefactos recuperados junto con la cerámica. Se encontraba el cráneo de un adulto, tal vez masculino (fig. 2), que había sufrido una pérdida de dientes post mortem. También exhibe el tipo de deformación anular según Juan Imbeloni (1933) o circunferencial según Susan Antón (1989). Además hay una herramienta de tejido (wichuña) (fig. 3) confeccionada del asta de una taruka (Hippocamelus antisensis). Finalmente se encontraban dos artefactos líticos tallados (fig. 4) que pueden haber servido como boleadoras (liwi). Ambas 

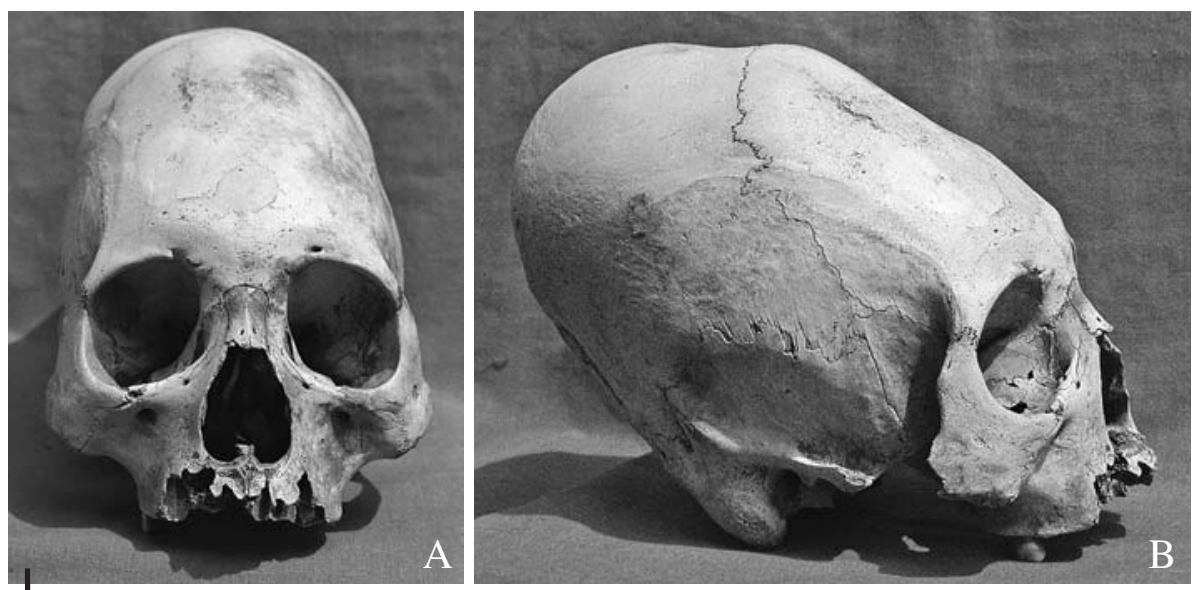

Figura 2 - Cráneo de adulto con deformación procedente de Coscopunta, Ancash. A) Vista frontal; B) Vista de perfil

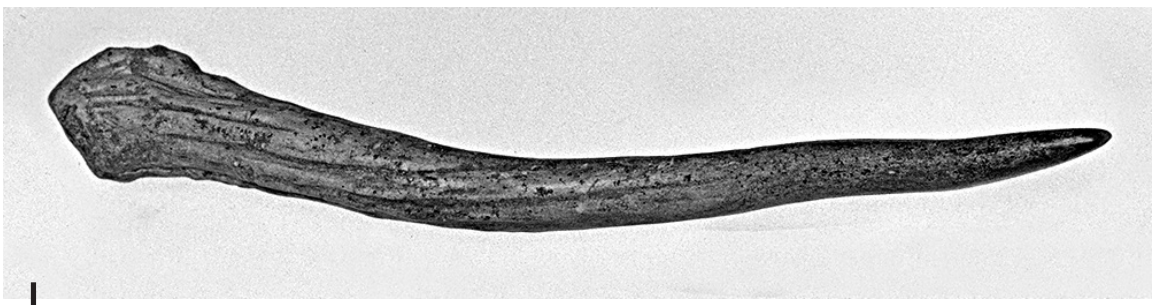

Figura 3 - Herramienta de hueso para tejido (wichuña) de Coscopunta, Ancash, Museo Arqueológico de Ancash (MAA)

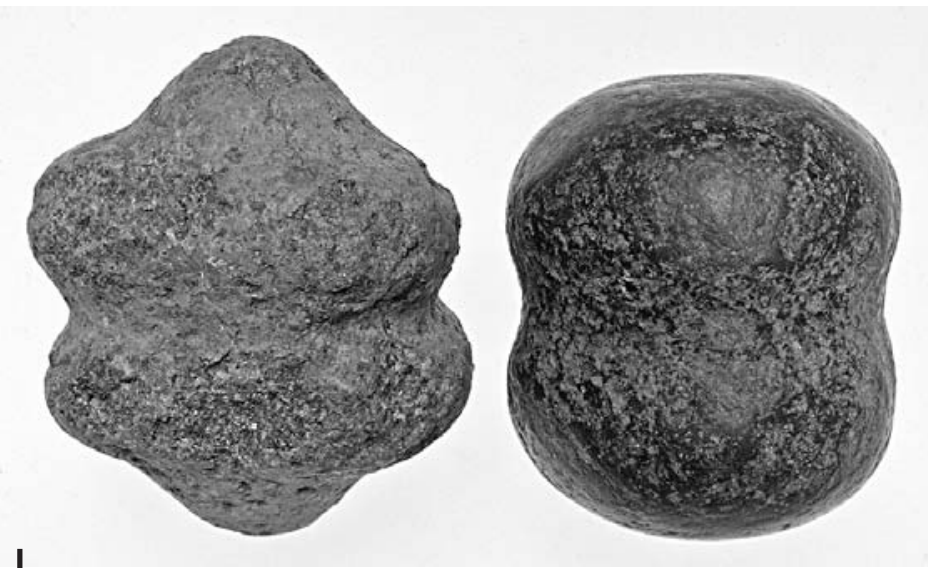

Figura 4 - Boleadoras líticas (liwi) procedentes de Coscopunta, Ancash, MAA 
ostentan una acanaladura central adecuada para atarlas. Ya que ninguno de los artefactos líticos muestra el desgaste asociado a las herramientas agrícolas, lo más probable es que hayan sido usados como armas de caza o guerra.

En agosto de 2006, a fin de recabar información adicional para este artículo, Burger viajó al Callejón de Huaylas para visitar Coscopunta y confirmar la proveniencia de la colección arqueológica en cuestión. Coscopunta aparece en la hoja cartográfica de Carhuaz editada por el Instituto Geográfico Nacional (1352 19-h) y está localizada a $3 \mathrm{~km}$ al oeste del pueblo de Anta; sus coordenadas son $9^{\circ} 21^{\prime} \mathrm{S}$ y $77^{\circ} 38^{\prime} \mathrm{W}$. Acompañado por el arqueólogo peruano Francisco Bazán, Burger ascendió las laderas de la Cordillera Negra, desde Anta hasta el pueblo de Pomacancha. Desde allí, ambos continuaron ascendiendo a pie casi durante 4 horas hasta llegar a Coscopunta.

De acuerdo con el GPS, la aldea está situada a 3633 msnm con las siguientes coordenadas UTM 896532N 211126E, Zona 18S, Datum WGS 1984. La actual aldea de Coscopunta está situada sobre una estrecha cresta dedicada al cultivo de productos altoandinos tales como papa y quinua; también cultivan trigo y cebada. Un pequeño grupo de construcciones de adobe proporciona albergue a las pocas familias que cultivan esta tierra.

Uno de los actuales agricultores, el señor Nemesio Cántaro, nacido en 1969, confirmó que —en el pasadolos materiales arqueológicos fueron encontrados en Coscopunta y que, ocasionalmente, continúan recuperándose tiestos cerca de la aldea durante el cultivo, aunque ninguno se encontraba visible sobre la superficie. Cántaro también identificó la localización de otros dos sitios arqueológicos cercanos que produjeron restos arqueológicos, pero ninguno de estos ha sido cultivado en tiempos recientes. Uno de ellos, Cotocancha, es bastante alto para el cultivo; mientras que el otro, Jircacancha, está cubierto por un bosquecillo. De los sitios arqueológicos cercanos a Coscopunta, solo el que está ubicado en la misma aldea corresponde a la descripción del agricultor que nos trajo la colección en 1979.

Uno de los rasgos arqueológicos inequívocos en la aldea de Coscopunta es un pilar lítico no trabajado o huanca, enterrado verticalmente en el centro del campo de cultivo (fig. 5). El huanca mide

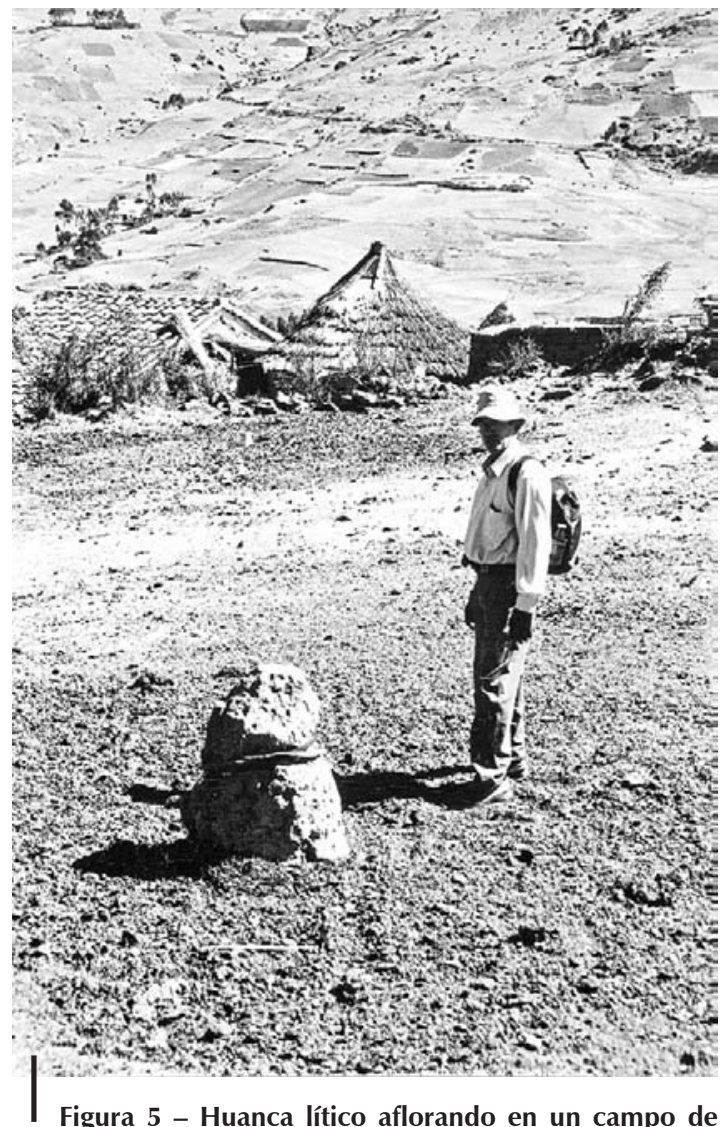

Figura 5 - Huanca lítico aflorando en un campo de cultivo (chacra) de la aldea de Coscopunta, Ancash (C) Richard Burger 
$75 \mathrm{~cm}$ de altura por $65 \mathrm{~cm}$ de ancho en su base. De acuerdo con Cántaro, se dice que el nombre del caserío, Coscopunta, proviene de los términos cosco, que significa lugar donde emerge el vapor de agua, y punta, que significaría punto o cresta. Cántaro dice que hay cuentos que la zona de la huanca fue una fuente de vapor y agua en el pasado y él cree en la veracidad de estas historias, la cual se la contaron sus abuelos y padres. Sin embargo, él nunca ha visto personalmente el vapor ni la irrupción de otro tipo de humedad de la tierra. Desde el punto de vista etimológico, el profesor Leonel Menacho López, especialista en el quechua de Ancash en la Universidad Nacional Santiago Antúñez de Mayolo, Huaraz, sugiere que el término cosco en Coscopunta podría derivarse de la palabra qusqi o qusquy que significa «aire raro; vapor que emite de un lugar» (Leonel Menacho López, comunicación personal, 2014). Aunque en Coscopunta hay muchos muros con mampostería de piedra, no se puede determinar con certeza si alguna de ellas es de data prehispánica.

Desde Coscopunta, es excepcional la vista de los picos glaciales del Huascarán y los nevados adyacentes de la Cordillera Blanca (fig. 6). Basados en la visita a Coscopunta tenemos como hipótesis de trabajo que los materiales arqueológicos descritos en este artículo pueden venir de ofrendas rituales enterradas alrededor de la piedra sagrada (huanca) de Coscopunta durante el Periodo Intermedio Tardío. Discutiremos esta hipótesis con más detalle posteriormente.

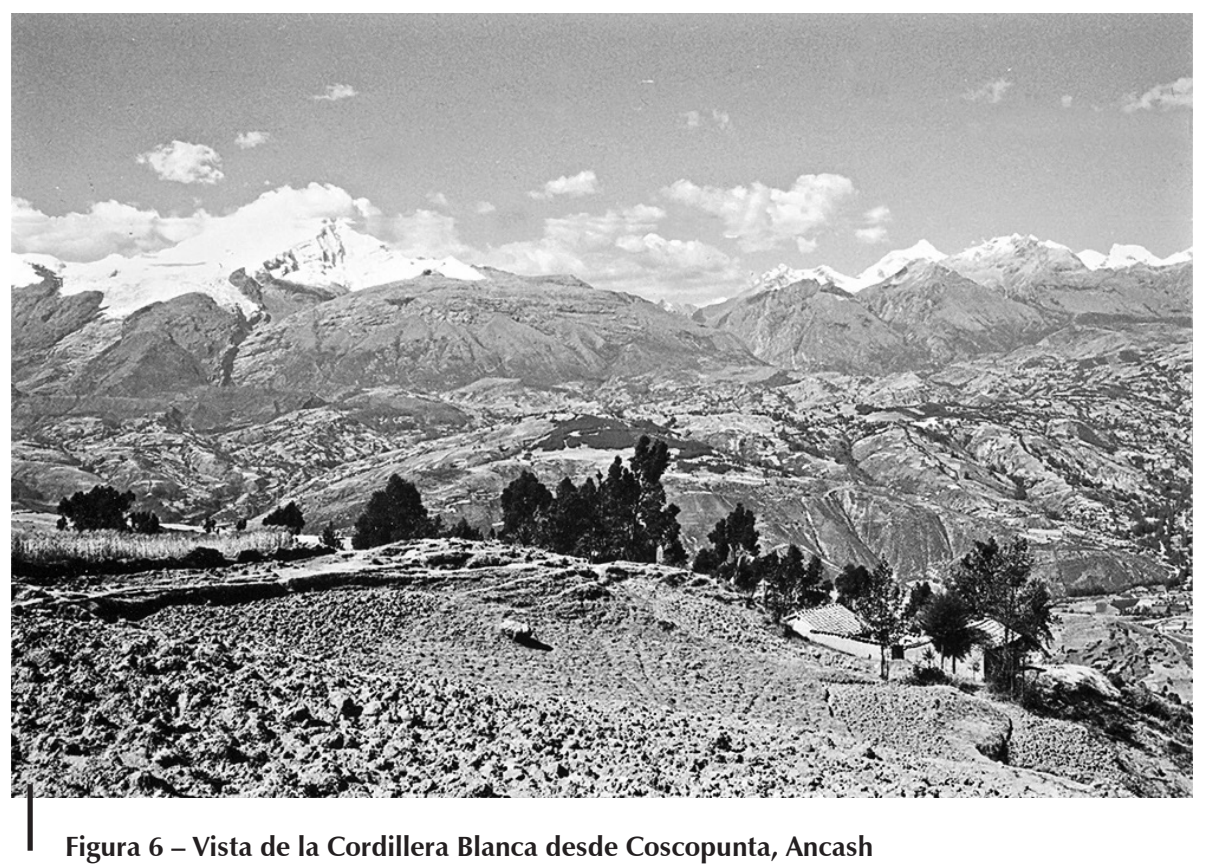

(c) Richard Burger 
Steven Wegner, un especialista en la arqueología de Ancash, se muestra escéptico ante esta hipótesis de trabajo. Piensa que la excelente condición de las vasijas y cráneo sugieren que han sido enterrados en cámaras de mampostería de piedra antes que en la tierra y que tales cámaras pueden haber existido en uno de los sitios cerca al moderno caserío de Coscopunta (Wegner, comunicación personal, 2013). Ademas, él notó la existencia de otro huanca en un campo de cultivo al este donde podría haber existido una cámara subterránea. Esta hipótesis alternativa sería consistente con la presencia del cráneo en buen estado, los dos artefactos de piedra y la herramienta de tejido en la colección Coscopunta. Todas hubieran podido estar presentes junto con la cerámica en una o más cámaras, tal vez con fines funerarios.

\section{EL ESTILO CERÁMICO DE LAS VASIJAS DE COSCOPUNTA}

La mayor parte de la cerámica de Coscopunta está ejecutada con un estilo rústico que se parece a muchos conjuntos del Periodo Intermedio Tardío descritos para la sierra norte y central del Perú. Las vasijas de Coscopunta se produjeron a través del modelado a mano, probablemente usando rollos y luego acabadas con el alisado y, ocasionalmente, el pulido de sus superficies. La cerámica local fue quemada en una atmósfera oxidante pero las frecuentes zonas oscuras producto del quemado atestiguan la carencia del control sobre la atmósfera de la quema. Algunas veces se usó engobe rojo o pintura roja sobre el exterior de las vasijas, pero frecuentemente se oculta o es completamente eliminado por las manchas de la quema. La cerámica es relativamente suave, con solo una dureza de 3/4 en la escala de Mohs como su moda estadística y varias vasijas tienen una dureza de $2 / 3$ (anexo 1). Aunque todas las vasijas tienen formas más o menos simétricas, la baja calidad de su producción resultó en vasijas ligeramente torcidas o asimétricas.

En la muestra de Coscopunta hubo más vasijas cerradas que abiertas; de hecho, el $81 \%$ de las vasijas de cerámica fueron cerradas. La forma más común de decoración plástica incluyó el appliqué (aplicado) de bandas y nódulos (protuberancias), círculos estampados y punteado. También hay evidencia de pintado y una botella muestra un modelado figurativo. Muchos de estos elementos decorativos y tecnológicos fueron ampliamente compartidos a lo largo de la sierra central y norte, pero fue distintiva la particular combinación de rasgos usados en cántaros, ollas, botellas y cuencos de Coscopunta. No hay evidencia que alguna de las vasijas fuera reparada o retocada antes de su entierro y, en el caso de las vasijas incompletas, no está claro si el daño se dio antes o después de su entierro en Coscopunta.

A continuación se proporciona un breve resumen y una descripción de las vasijas de Coscopunta. Están organizadas según su forma, y todas han sido ilustradas. Luego de la descripción de las vasijas se presenta una corta discusión sobre los patrones estilísticos y cómo se relacionan con otros conjuntos del Periodo Intermedio Tardío de la sierra de Ancash y otras zonas. 


\section{1. Cuenco 1 (fig. 7)}

Esta forma de cuenco con pedestal representado por un solo objeto es globular, poco profundo, con lados convexos y borde redondeado. Se sienta sobre una base con pedestal cóncavo. Su superficie exterior está decorada con cuatro zonas achuradas (cross-hatching) pintadas con un pigmento oscuro (gris a negro) sobre el fondo anaranjado de la superficie oxidada de la vasija. Las zonas decoradas están separadas por una banda vertical sin decorar. El interior del cuenco se dejó sin pintar y tiene menos acabado que el exterior.
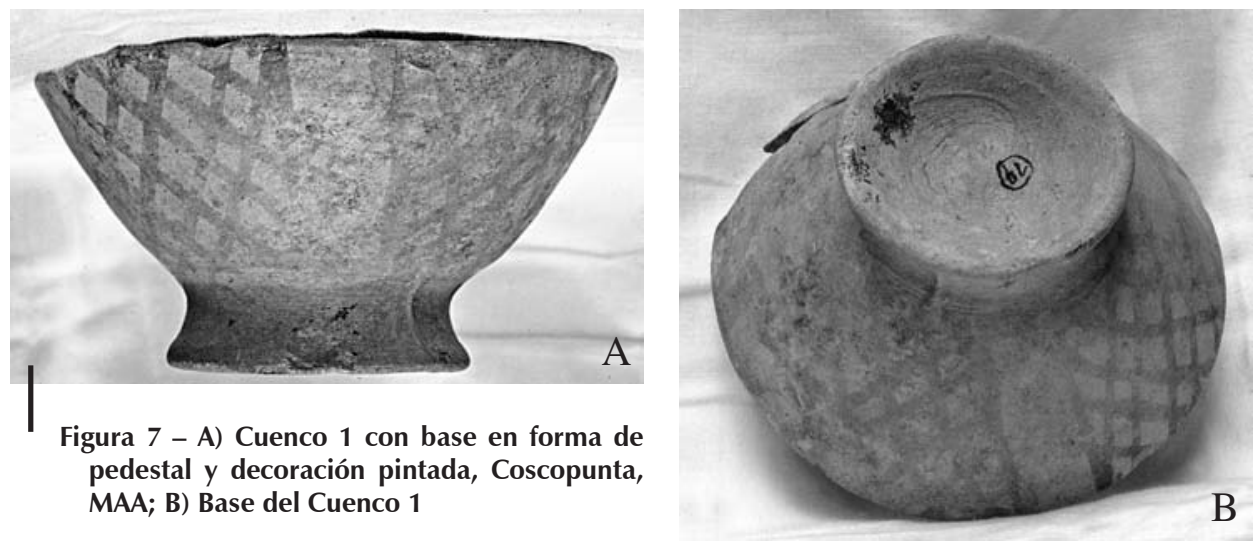

\section{2. Cuenco 2 (fig. 8)}

Esta forma de cuenco apedestalado se parece al Cuenco 1 pero se dejó sin decorar y su pedestal es más corto, de forma cilíndrica antes que cóncava. Como en el caso del Cuenco 1, la superficie fue pulida pero el acabado resultó desigual y las huellas del pulido permanecen visibles. Hay trazas de engobe rojo en el exterior e interior pero las zonas ennegrecidas por la cocción oscurecen la coloración.

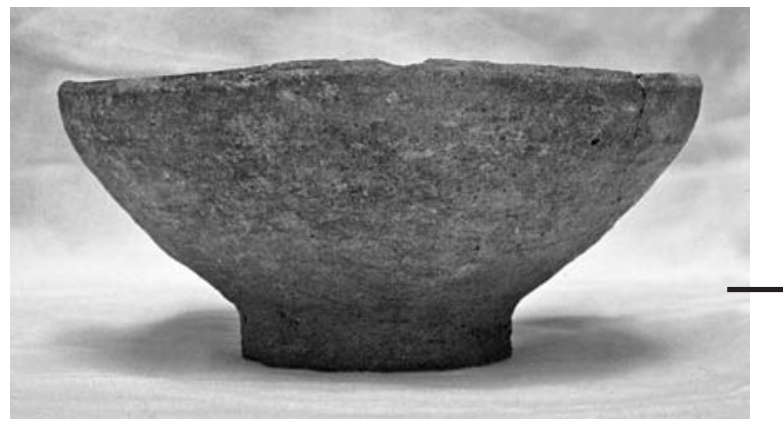

Figura 8 - Cuenco 2 con base en forma de pedestal, Coscopunta, MAA 


\section{3. Cuenco 3 (fig. 9)}

Esta forma de cuenco, representado por un solo objeto, es un cuenco globular de paredes bajas, lados convexos, borde redondeado y una base aplanada. La superficie exterior llana está defectuosamente alisada con más pulimento en el exterior que en el interior; la variación de los colores en la superficie refleja los efectos de una cocción desigual.

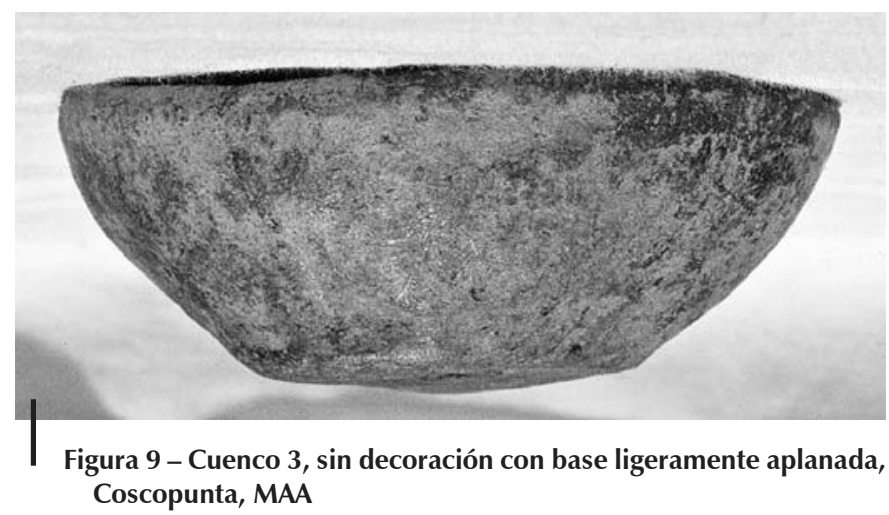

\section{4. Cuenco 4 (fig. 10)}

Este cuenco tiene forma globular de paredes bajas, lados convexos, borde redondeado e irregular y una base redondeada. Una cocción irregular ha dejado manchas negras sobre la superficie oxidada de color anaranjado.

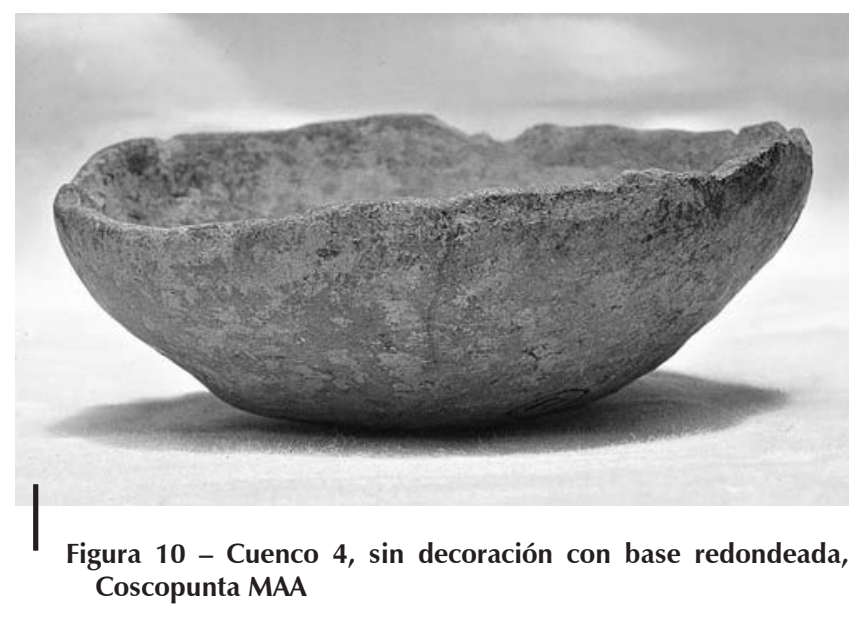




\section{5. Botella 1 (fig. 11)}

La vasija más elaborada de la colección Coscopunta es una botella de doble cuerpo. Cada uno de los dos cuerpos mellizos irregulares se estrecha hacia un alto cuello vertical que finaliza en un borde evertido. La base de los cuellos fue decorada con bandas que contienen pequeños círculos estampados y pequeños nódulos impresos con círculos estampados profundos. En su forma y decoración los cuerpos de la botella parecen los cántaros de cuello largo de Coscopunta. Una rotura en la botella hace posible observar que los dos cuerpos se hicieron independientemente y luego fueron unidos por un tubo cilíndrico de modo que el líquido pudiera pasar entre ellos. Esta conexión física entre las cámaras fue ocultada con arcilla alisada, uniendo las dos superficies de los cuerpos de la botella. Sobre un lado de la botella, un asa aplanada horizontal conecta los dos cuerpos. Sobre el otro lado de la botella, la conexión entre los dos cuerpos sostuvo una figura de animal modelada. Desafortunadamente, solo permanecen intactas sus dos piernas frontales con sus patas y garras con uñas incisas. La botella está despintada pero hay abundantes manchas de cocción.
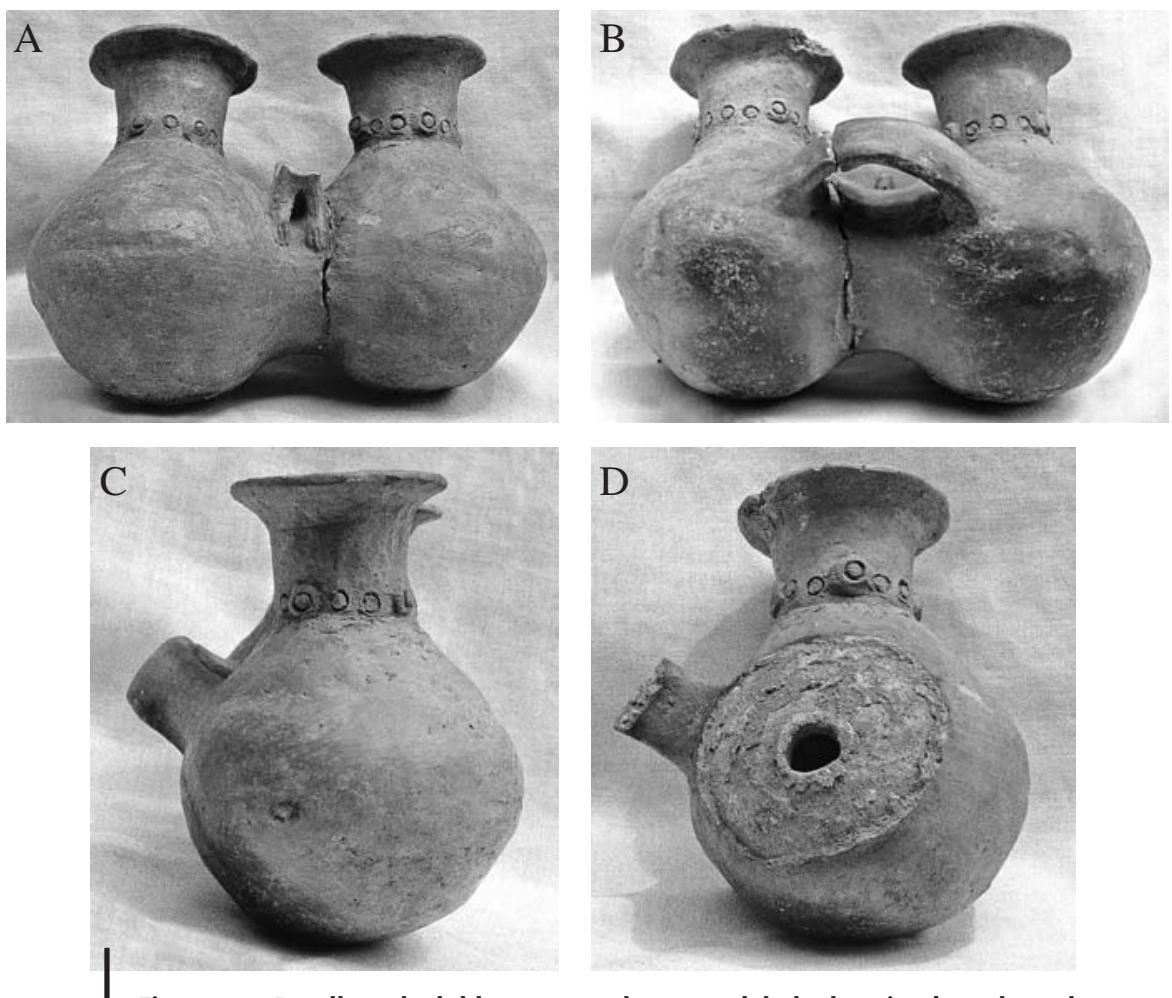

Figura 11 - Botella 1, de doble cuerpo, adorno modelado de animal, asa lateral aplanada y bandas horizontales con círculos estampados, Coscopunta, MAA 


\section{6. Botella 2 (fig. 12)}

Esta botella tiene un color negro uniforme y una consistente pasta gris, con un quemado en atmósfera reductora. Su cuerpo es globular y acaba en un cuello cilíndrico incompleto. Una sola asa trenzada conecta el cuello de la botella a la parte superior del cuerpo. Sobre el lado opuesto de la botella, el cuerpo superior está decorado con un pequeño nódulo protuberante. Es evidente un ligero bisel horizontal en la sección media de la botella y esto sugiere una producción en un molde de dos piezas. El acabado de la superficie es parejo comparado con las otras vasijas e incluso en algunos lugares alcanza un brillo bajo. Creemos que no fue producida en Coscopunta o cerca del lugar debido a que esta vasija es única en su quemado, acabado de superficie, forma asimétrica, color, tipo de asa, decoración y tecnología de producción. De hecho, en muchos de sus rasgos, la pieza se parece a las botellas tardías de la costa norte del Perú (p. ej. Martínez, 1986: lámina 12d). Los rasgos compartidos incluyen el uso de cocción reductora, la preferencia por las botellas de una sola asa asimétrica, el uso de sólidas asas trenzadas, la superficie negra totalmente pulida, cuellos de botella cilíndricos y el ligero bisel en la mitad del cuerpo (como resultado de la unión de dos secciones consecuencia del uso de un molde de dos piezas). Estos rasgos son típicos de la fase Sicán Tardío en Batán Grande (Shimada \& Ono, 1994: 178, 180) y Fase Medio (Middle Phase) en Chotuna y Chornancap (Donnan, 1990: 266-267, fig. 12d), ambos en el drenaje Lambayeque-La Leche y por lo tanto, nuestra hipótesis de trabajo es que esta vasija representa una importación costeña a Coscopunta. Donnan (1990: 266) estima a su Fase Medio en Chotuna y Chornancap fecha entre AD 1100 a 1300; Shimada (1990: 354) calcula una edad de AD 1100 a 1350 por Sicán Tardío. Ambas fechas están dentro del Intermedio Tardío y son consistentes con nuestra conclusión que la cerámica de Coscopunta fecha al Intermedio Tardío. Izumi Shimada (comunicación personal, 2013) confirma la semejanza de la Botella 2 a la cerámica Sicán Tardío de Lambayeque-
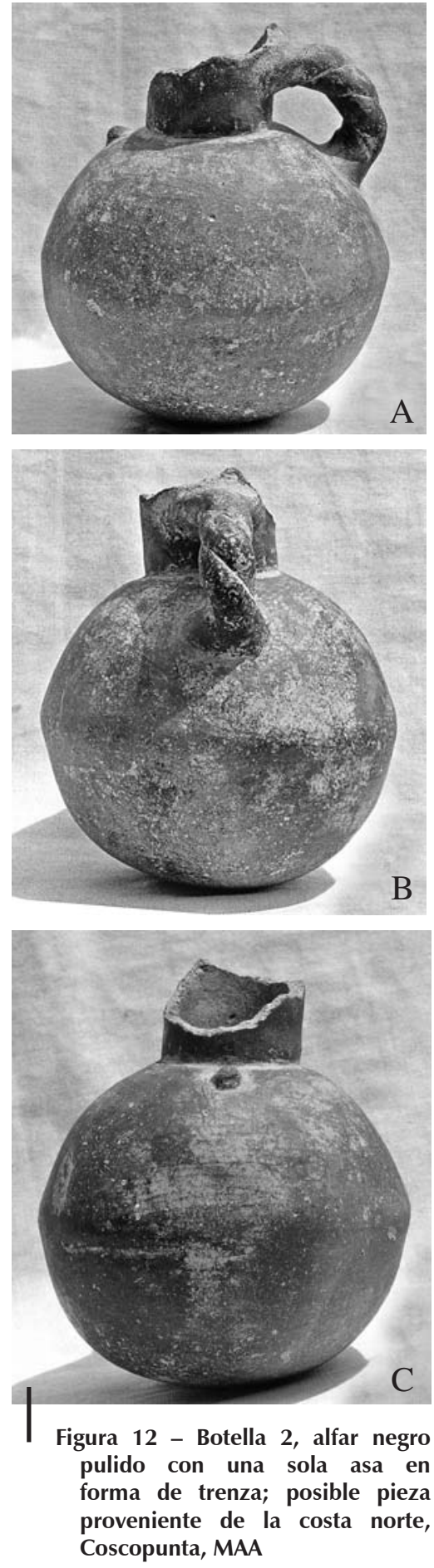
La Leche, pero él contempla la posibilidad de que la pieza de Coscopunta pueda ser una imitación de este estilo producido fuera del drenaje Lambayeque-La Leche. Él indica, por ejemplo, que hay un componente de cerámica negra de producción local en el sitio de El Purgatorio en el valle de Casma que fue inspirado por el estilo Sicán.

Melissa Vogel, la investigadora de El Purgatorio y otros sitios tardíos en Casma, confirma que la botella negra de Coscopunta ha sido fabricada según el estilo tardío de Casma (Melissa Vogel, comunicación personal, 2014).

\section{7. Cántaro 1 (figs. 13, 14 y 15)}

Estos tres cántaros de mediano tamaño tienen un cuerpo globular y un alto cuello cóncavo que remata en un borde fuertemente evertido. Carecen de asas. Hay evidencia de engobe rojo total, oscurecido en algunas secciones por las abundantes manchas de cocción. En la colección Coscopunta existen dos ejemplares casi completos de este tipo de cántaros y uno al que le falta el cuello. En ambos casos de vasijas completas, el cuerpo de la vasija está decorado con nódulos aplicados que han sido hendidos; estos nódulos están igualmente espaciados en la sección superior del cuerpo. Difieren principalmente en la decoración del cuello del cántaro. En uno (fig. 13), la base del cuello del cántaro está adornada con dos filas horizontales de pequeños círculos, ubicados uno muy cerca del otro. En el otro (fig. 14), la base del cuello del cántaro muestra una banda aplicada sobre la que se ha impreso una sola fila horizontal de pequeños círculos estampados, ubicados uno muy cerca del otro. El cuerpo del último cántaro (fig. 15), similar a la figura 13 pero carente de nódulos aplicados, constituye un tercer ejemplo de esta forma de vasija.

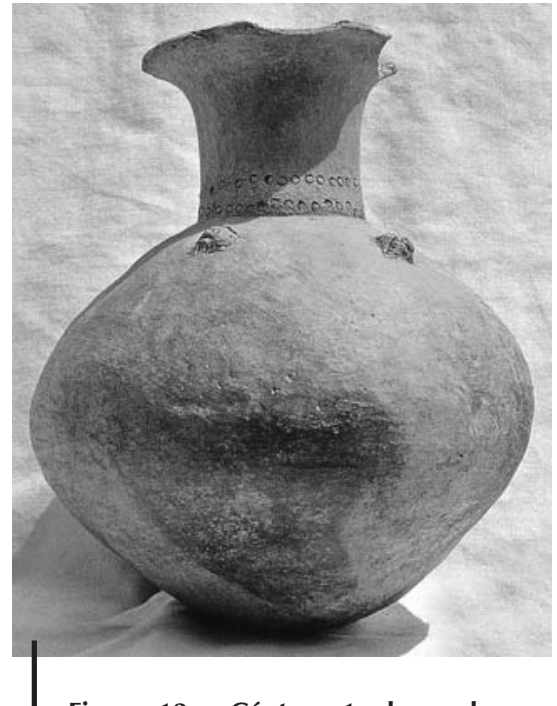

Figura 13 - Cántaro 1, decorado con pequeños nódulos aplicados y dos bandas horizontales de círculos estampados, Coscopunta, MAA

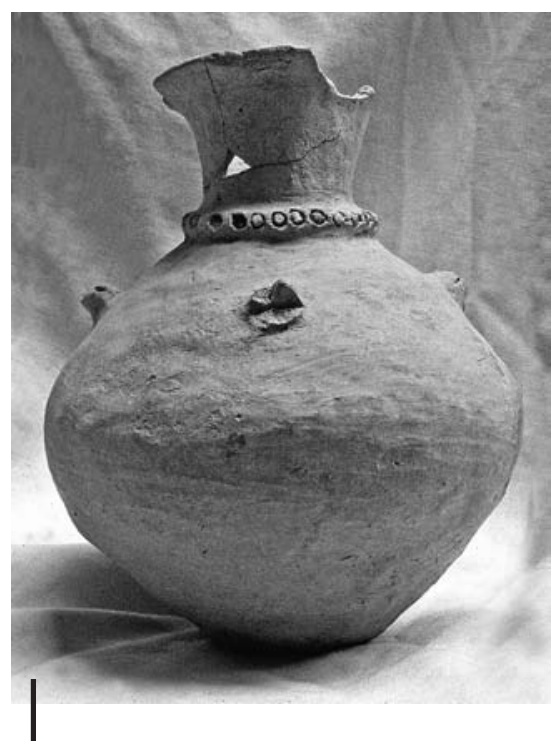

Figura 14 - Cántaro 1, decorado con nódulos aplicados e incisos y una banda horizontal aplicada con círculos estampados, Coscopunta, MAA 


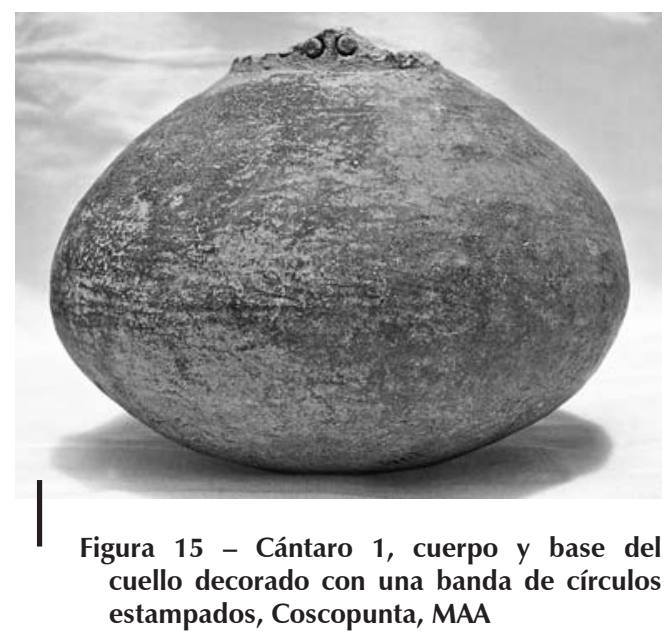

\section{8. Cántaro 2 (fig. 16)}

Este cántaro de mediano tamaño tiene la forma similar a la del Cántaro 1 pero tiene dos asas simétricas verticales que conectan la sección superior del cuerpo con la sección media del cuello cóncavo del cántaro. Una banda en la base del cuello del cántaro es cóncava, así se produjo una sección compuesta. La sección media está decorada con una sola fila horizontal de pequeños círculos estampados y dos nódulos protuberantes aplicados, ubicados centralmente e impresos con un solo círculo. Esta decoración es muy similar a la usada en la Botella 1. El Cántaro 2 también tiene incisiones en zigzag hechas en pasta seca formando ocho líneas verticales en el cuello. Además, la vasija está adornada con bandas verticales y paralelas de pintura roja en el interior y exterior del cuello, y otras bandas pintadas que pasan encima de las asas y siguen bajando hacia el cuerpo. En contraste con el Cántaro 1, el Cántaro 2 carece de nódulos aplicados sobre su cuerpo. Como en otras vasijas, el Cántaro 2 tiene una forma ligeramente irregular y abundantes manchas de cocción.

\section{9. Cántaro 3 (figs. 17 y 18)}

Este cántaro llano de tamaño medio muestra un cuerpo globular, un cuello alto cóncavo y dos asas cintadas verticales. A diferencia de los Cántaros 1 y 2 no hay decoración sobre el cuerpo o cuello de la vasija y, a diferencia del Cántaro 2, las asas de correa están localizadas en la sección media del cuerpo. De los dos ejemplares de las vasijas del tipo Cántaro 3, uno (fig. 17) fue manufacturado con mayor cuidado y tiene un mejor acabado que el otro (fig. 18). Sobre estas vasijas aparecen trazas de engobe rojo y abundantes manchas de cocción, igual que en los otros cántaros. 

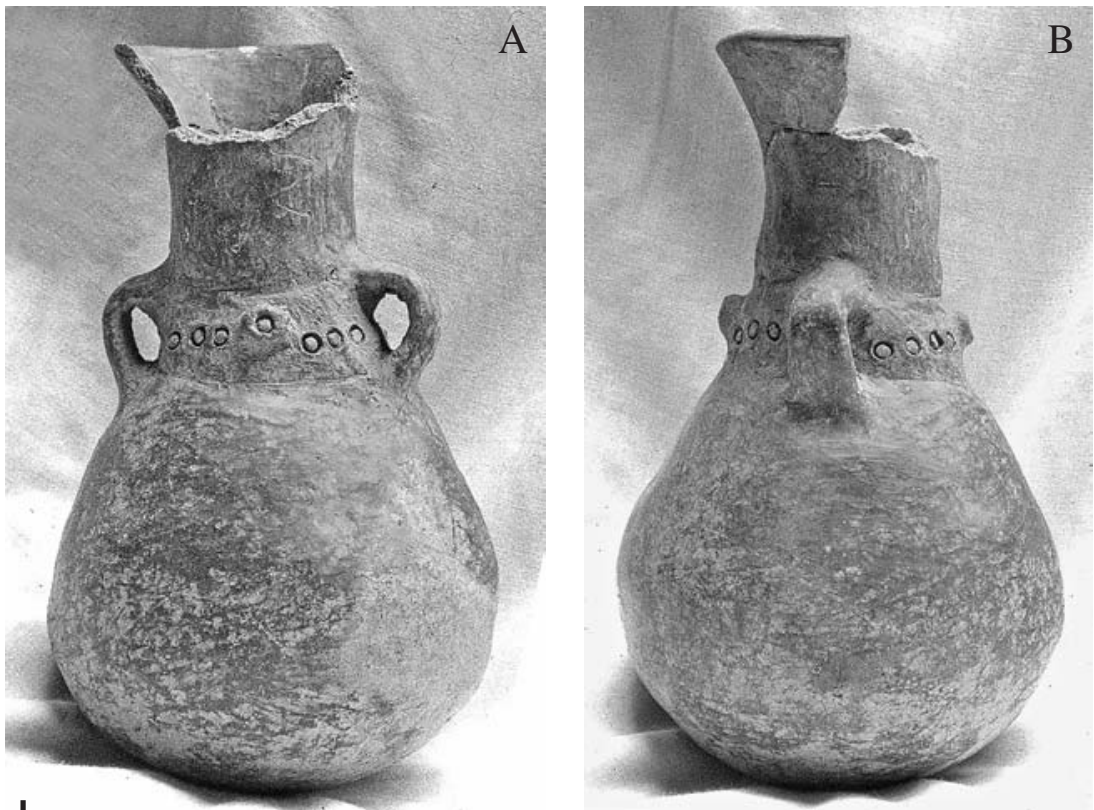

Figura 16 - Cántaro 2, con asas de correa verticales, decorado con una banda horizontal de círculos estampados y nódulo aplicado con círculo estampado, Coscopunta, MAA
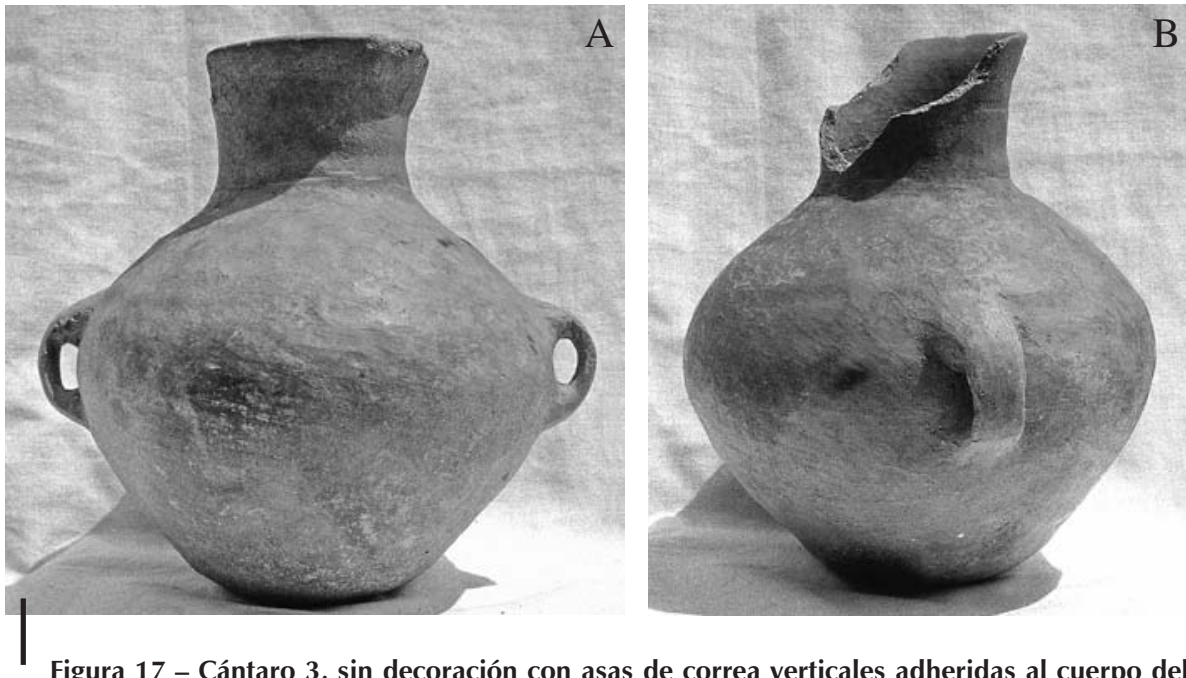

Figura 17 - Cántaro 3, sin decoración con asas de correa verticales adheridas al cuerpo del cántaro, Coscopunta, MAA 

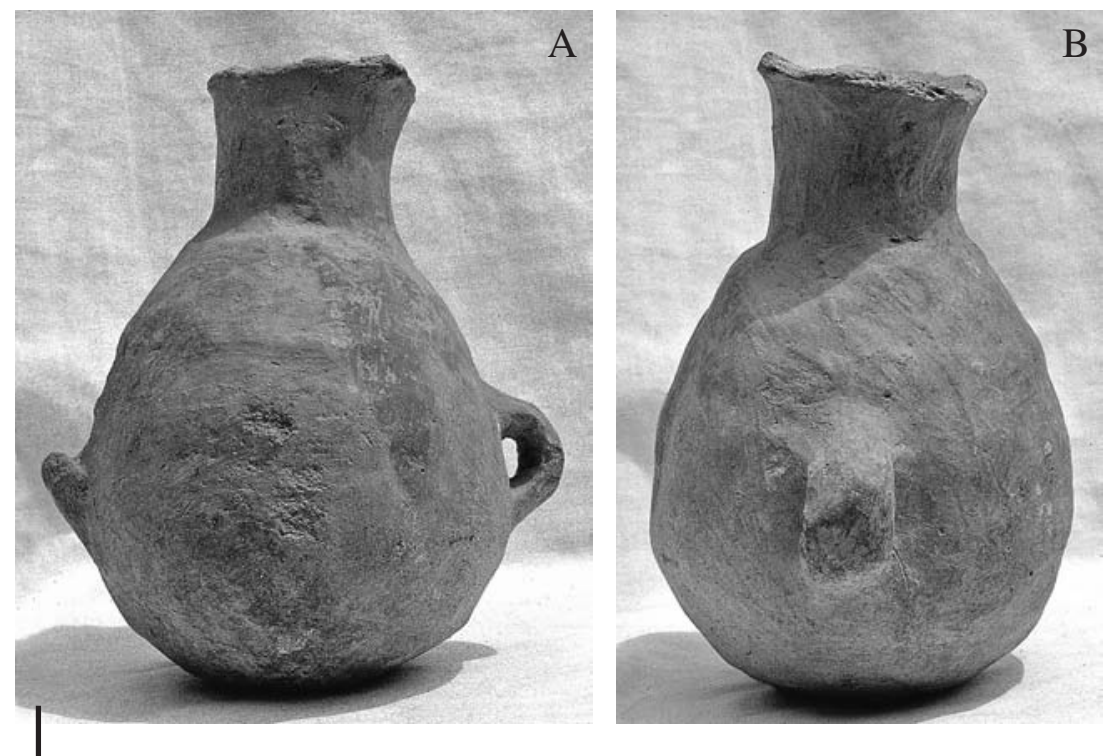

Figura 18 - Cántaro 3, sin decoración con asas de correa verticales adheridas al cuerpo del cántaro, Coscopunta, MAA

\section{10. Cántaro 4 (fig. 19)}

En la colección de Coscopunta, esta forma de cántaro de tamaño mediano está representada solo por un fragmento de cuello; el cuerpo se ha perdido. El cuello, inusualmente largo, tiene el lado ligeramente cóncavo que remata en una banda ligeramente convexa, dando a la vasija una forma compuesta. La ancha banda horizontal inferior está decorada con cuatro filetes aplicados en forma de protuberancias acanaladas dispuestas verticalmente sobre el cuello del cántaro. A diferencia de los otros cántaros de Coscopunta, esta vasija ha sido uniformemente quemada en atmósfera oxidante dando un color marrón claro y, a diferencia de la cerámica local, carece de trazas de engobe rojo y manchas de cocción. Su forma es más regular (y menos rústica) que la mayoría de las vasijas de Coscopunta. Estos rasgos sugieren que el alfar fue producido fuera del área de Coscopunta y la distintiva decoración del cuello del cántaro tiene muchas similitudes a la cerámica de la fase Chakwas de la Cordillera Negra al oeste de Huaraz, en las cabeceras del río Casma (Lau, 2010: 242, fig. 87O, R; 244, fig. 88A).

\section{11. Cántaro 5 (figs. 20 y 21)}

Este pequeño cántaro tiene un cuello corto cilíndrico, base redondeada y un par de asas cintadas simétricamente colocadas conectando la mitad del cuello del cántaro a la porción superior del cuerpo. El ejemplo ilustrado en la figura 20, 


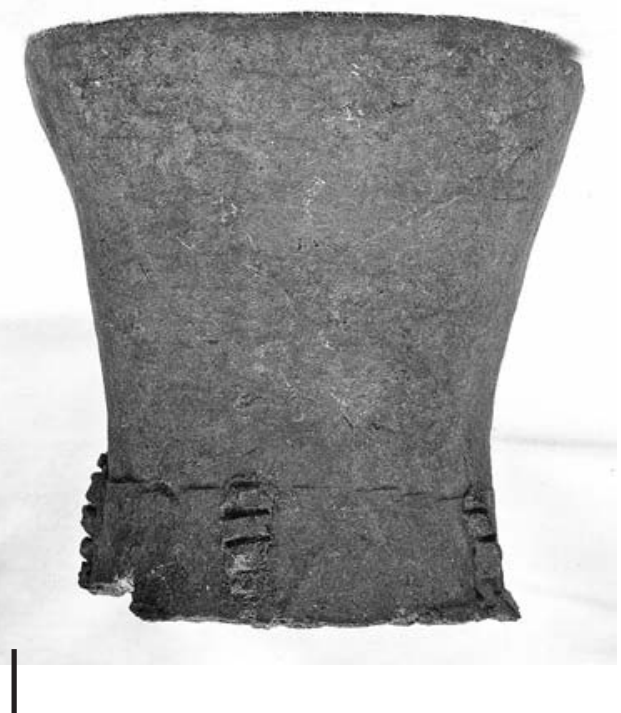

Figura 19 - Cántaro 4, cuello de vasija fragmentado, decorado con filetes aplicados verticalmente con incisiones horizontales, Coscopunta, MAA; posiblemente importado del área de Chinchawas, Cordillera Negra

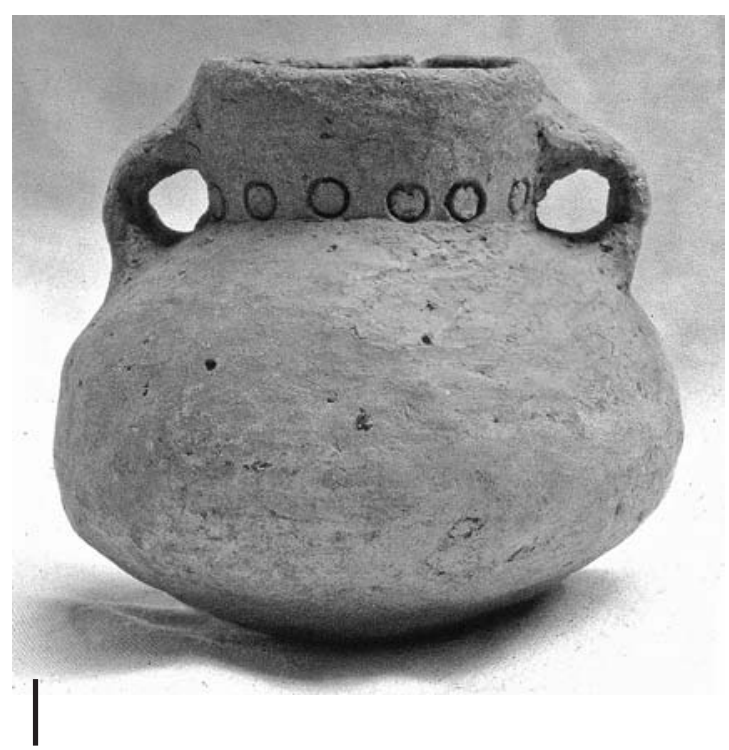

Figura 20 - Cántaro 5, con asas de correa verticales adheridas al cuello de la vasija y decorado con una banda de círculos estampados, Coscopunta, MAA
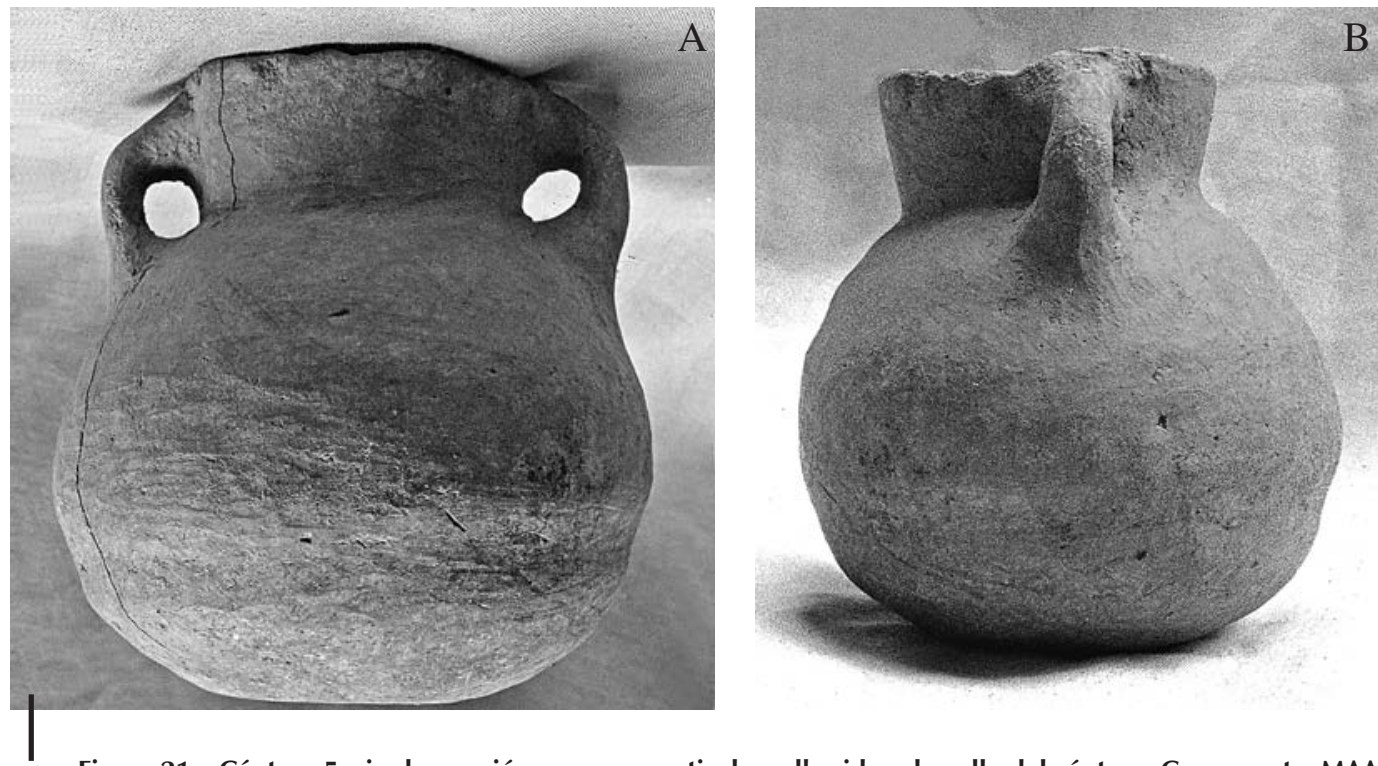

Figura 21 - Cántaro 5, sin decoración con asas verticales adheridas al cuello del cántaro, Coscopunta, MAA 
como muchos cántaros, está decorado con una sola banda de pequeños círculos estampados bordeando la parte inferior del cuello de la vasija. También se parece a la mayor parte de los otros cántaros en su superficie alisada desigualmente, un aspecto mate irregular y la presencia de manchas de cocción. En la colección de Coscopunta existe un segundo ejemplar de esta forma de pequeño cántaro pero carece de algún tipo de decoración (fig. 21). También varía del otro en que sus asas son redondeadas en vez de aplanadas.

\section{12. Cántaro 6 (fig. 22)}

Este pequeño cántaro tiene un cuello corto expandido con paredes cóncavas. Un simétrico par de asas aplanadas conectan la parte inferior del cuello del cántaro con la parte superior del cuerpo de la vasija. La vasija está burdamente acabada y muestra evidencia de engobe rojo y numerosas manchas de cocción. Lo que distingue a esta vasija es su inusual decoración. Una banda aplicada circunda la base del cuello del cántaro con dos filas paralelas de grandes punteadas circulares ubicadas sobre ambos lados de esta banda. Una tercera fila de punteadas circulares fue inscrita inmediatamente debajo del labio del cántaro. Sobre la banda aplicada y sobre el mismo labio se encuentran pequeños nódulos circulares aplicados, cada uno con punteadas centrales.
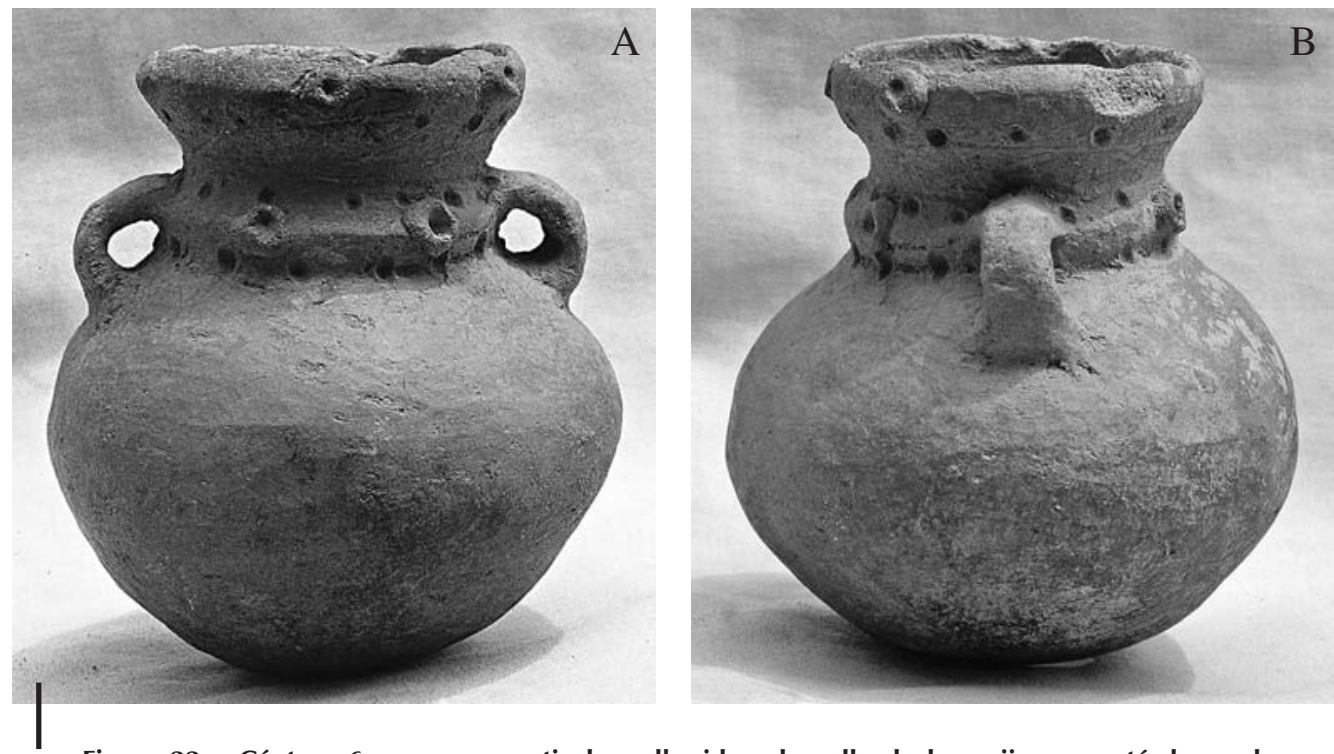

Figura 22 - Cántaro 6, con asas verticales adheridas al cuello de la vasija que está decorado con nódulos aplicados con una gran puntada central y tres bandas horizontales de puntadas profundas, Coscopunta, MAA 


\section{13. Cántaro 7 (fig. 23)}

Este pequeño cántaro sin decoración tiene un cuello cóncavo corto, base redondeada y asas cintadas verticales adheridas a la parte superior del cuerpo del cántaro.

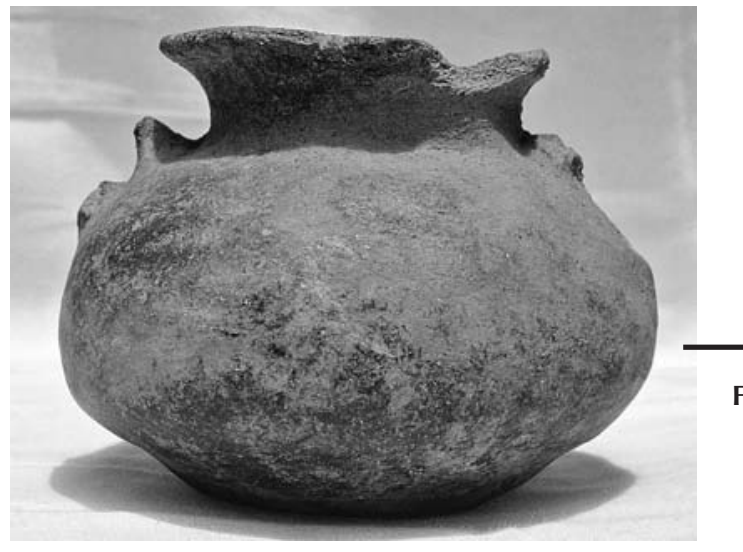

Figura 23 - Cántaro 7, sin decoración con cuello corto y asas laterales verticales adheridas a la parte superior del cuerpo, Coscopunta, MAA

\section{14. Cántaro 8 (figs. 24 y 25)}

Hay dos ejemplares de un pequeño cántaro sin decoración, cuello corto y asas cintadas conectando el cuerpo al cuello del cántaro. Es común observar engobe rojo y manchas de cocción, así como, un acabado desigual y forma irregular. Como en muchos otros tipos de cántaros, es visible un ligero aplanamiento en la base de la vasija.
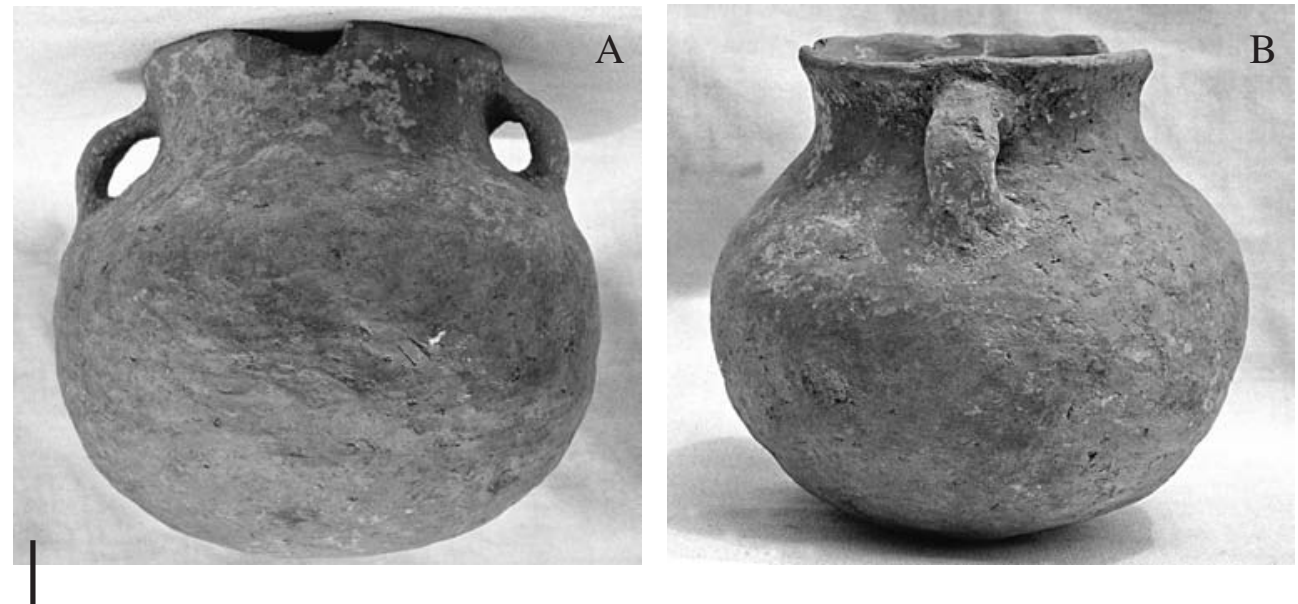

Figura 24 - Cántaro 8, sin decoración con cuello corto y asas laterales verticales adheridas al cuello, Coscopunta, MAA 

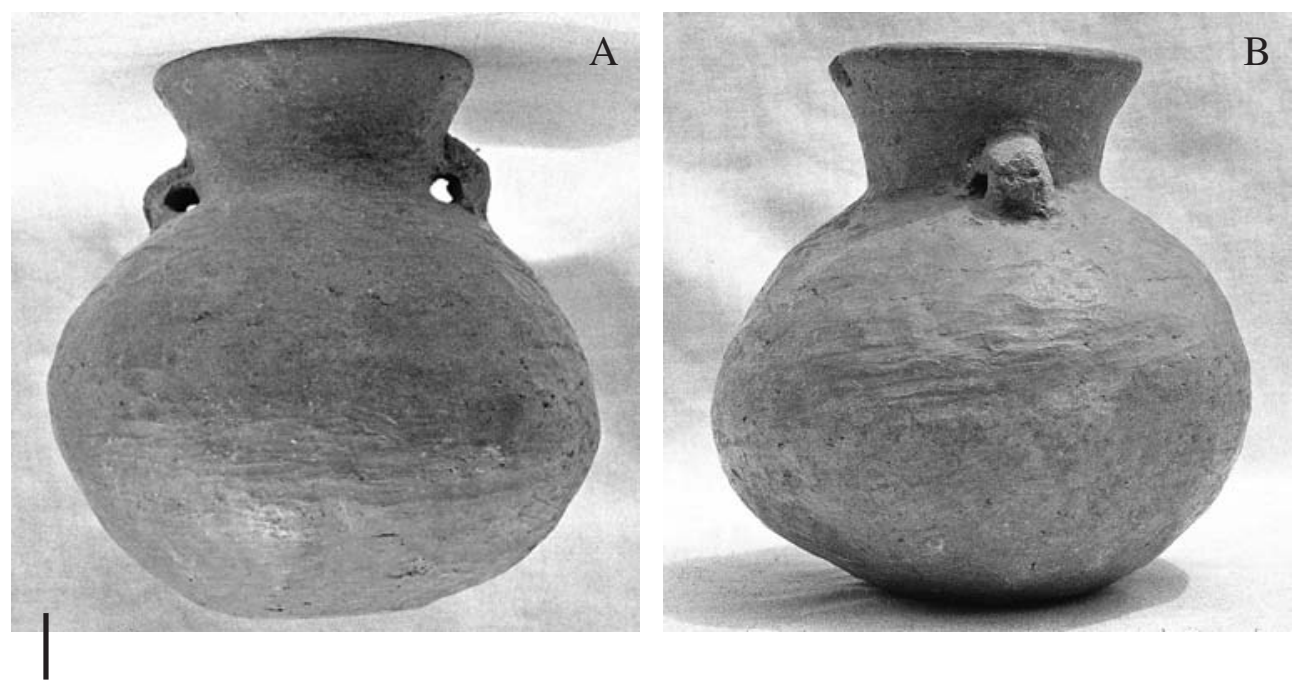

Figura 25 - Cántaro 8, sin decoración con cuello corto y pequeñas asas verticales adheridas a la parte baja del cuello, Coscopunta, MAA

\section{15. Cántaro 9 (fig. 26)}

Este pequeño cántaro único tiene un cuello muy corto y borde evertido con paredes cóncavas. Como los otros cántaros, tiene un par de asas cintadas, pero estas unen la parte superior del cuerpo de la vasija y la boca del cántaro. La sección superior del cuerpo globular está decorada con nódulos que contienen pequeños círculos. Este tipo de decoración recuerda a la encontrada sobre el Cántaro 2 (fig. 16), aunque los nódulos son más anchos. El tratamiento de superficie tiene una mezcla de engobe rojo, manchas de cocción y acabado irregular que tipifica a la mayor parte de las vasijas de la colección Coscopunta.

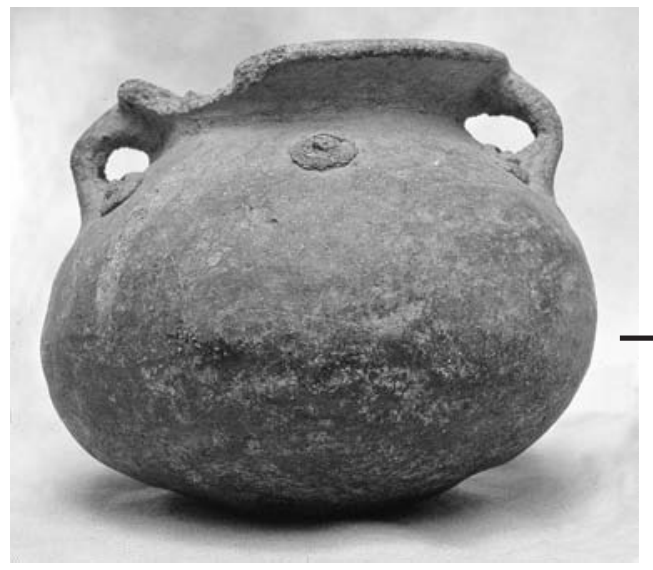

Figura 26 - Cántaro 9, cántaro de cuello corto con asas laterales verticales adheridas al borde de la boca del cuello y decorado con aplicaciones circulares estampadas con pequeños círculos, Coscopunta, MAA 


\section{16. Olla 1 (fig. 27)}

En la colección de Coscopunta, solo contamos con una pequeña olla de cocina con una identificación funcional tentativa. Esta vasija es globular con una ancha boca ligeramente evertida. Carece de asas y decoración. A diferencia de la mayoría de las otras vasijas, esta pieza es de color negro pero su color exterior oscuro puede deberse, parcialmente, al carbón de su uso en la cocina. El acabado de la superficie es desigual y de aspecto mate.

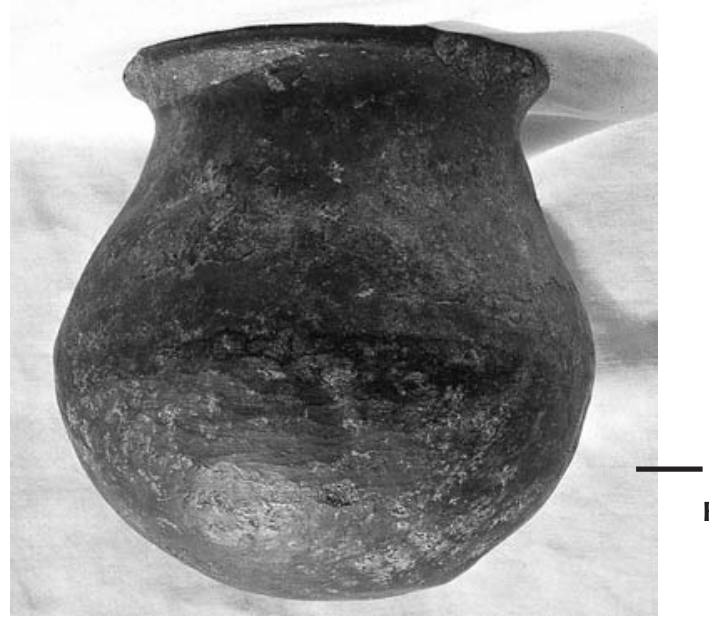

Figura 27 - Olla 1, pequeña olla de cocina sin decoración con borde evertido, Coscopunta, MAA

\section{DISCUSIÓN}

La cerámica recuperada en Coscopunta consiste de un gran número de cántaros de tamaño medio y pequeño, un par de botellas, unos pocos cuencos chicos y una sola olla de cocina. Los cántaros y botellas fueron diseñados para guardar y servir bebidas y, en menor grado, los cuencos para servir alimentos sólidos o tal vez líquidos. El pequeño tamaño de las vasijas sugiere que fueron concebidas para proveer raciones para uno o dos individuos antes que para atender la demanda de un grupo grande, como una reunión para banquetes. Igualmente, los cuencos son pequeños y adecuados solo para un individuo. Dado el contexto en el cual fue supuestamente encontrada la cerámica es concebible que estas vasijas alguna vez hayan contenido ofrendas de chicha o comida a las fuerzas sobrenaturales representadas por el huanca de Coscopunta. Esta interpretación será discutida con más detalle al final del artículo.

Como grupo, los ceramios parecen constituir un conjunto del Periodo Intermedio Tardío dominado por alfarería producida localmente. Sin embargo, no es un conjunto normal. Cuando se compara con el conjunto de cerámica del Periodo Intermedio Tardío del cercano sitio de Chinchawas, el conjunto de Coscopunta 
parece adolescer de vasijas de tamaño grande y, por el contrario, estar representado por vasijas para almacenar y servir líquidos.

Con la excepción de dos piezas, la mayor parte de la vasijas (i.e., 90\%) se produjeron con el mismo proceso técnico y siguiendo las mismas convenciones estilísticas. Parece probable que hayan sido hechas en el área de Coscopunta. A pesar de esto, casi no hay dos vasijas iguales y dada la diversidad de las formas y la decoración, no parece haber la clase de estandarización que con frecuencia acompaña al especialista a tiempo completo. Por el contrario, la baja calidad de la producción cerámica y su gran variabilidad sugiere que muchas familias estuvieron involucradas en hacerla y que esta se dio en una pequeña escala, quizás a nivel doméstico. Es probable que no involucrase una especialización a tiempo completo. Hemos sugerido, anteriormente, que los materiales de Coscopunta datan del Periodo Intermedio Tardío (ca. AD 1000-1430). Como no existen medidas radiocarbónicas de Coscopunta, esta conclusión se basa en una comparación estilística entre el estilo local de Coscopunta a otros sitios donde existen secuencias de cerámica asociadas a medidas radiocarbónicas y/o con estratigrafía. La secuencia relativa de cerámica más detallada para la prehistoria posformativa en el Callejón de Huaylas es la de George Lau en base a sus excavaciones en Chinchawas. Esta secuencia, basada en estratigrafía y fechas C14, tiene cuatro fases que abarcan el Periodo Intermedio Temprano, el Horizonte Medio y el Periodo Intermedio Tardío. Cuando se compara la cerámica de Coscopunta con la de Chinchawas, no queda duda que se asemeja a la fase Chakwas desde el punto de vista de su tecnología de producción, formas de vasijas y adorno. De acuerdo con Lau, la ocupación de la fase Chakwas en Chinchawas se inicia alrdedor de AD 1000. La correlación temporal entre la fase Chakwas y la cerámica de Coscopunta se refuerza con la presencia anteriormente mencionada (fig. 19) de un cántaro de tamaño mediano en el estilo de la cerámica Chakwas que parece traido a Coscopunta de la zona de Chinchawas. Es importante notar que las dos fases descritas por Lau para el Horizonte Medio en Chinchawas (Chinchawasi 2 [ca. AD 700-850] y Warmi [ca. AD 850-950]) tienen menos en común con el estilo de cerámica encontrada en Coscopunta.

Además, como hemos notado, la aparente presencia de una vasija importada (fig. 12) de la costa norte entre la colección de Coscopunta que corresponde en Lambayeque a la fase Sipán Tardío (ca. AD 1000-1350) o Lambayeque Fase Medio (ca. AD 1100-1300) confirma la datación estilístíca de la cerámica Coscopunta al Periodo Intermedio Tardío.

La evidencia que indica una fecha relativa del Intermedio Tardío para las vasijas Coscopunta no es soprendente. La mayor parte de las vasijas en la colección Coscopunta comparten elementos generales con el llamado estilo Aquilpo, denominado así por Vescelius y Amat, quienes fecharon al Intermedio Tardío en base a excavaciones estratigráficas en el Callejón de Huaylas. También, hay numerosas semejanzas entre la cerámica local de Coscopunta y la cerámica de estilo Casma, sobre todo el componente referido como Casma Inciso, de la costa entre los valles de Chao en el norte y Huarmey en el sur. Entre las semejanzas compartidas por la cerámica Coscopunta y Casma Inciso hay una preferencia 
por alfares anaranjados producidos por oxidación, la importancia de cántaros de cuello mediano y largo y la preferencia por el adorno plástico, sobre todo la decoración de los cuellos de cántaros. El estilo Casma favorece cuellos de cántaros adornados con líneas de círculos estampados en su parte inferior y pequeños aplicados cerca del borde, elementos que hemos visto en la cerámica tardía del Callejón de Huaylas. También cabe mencionar la presencia de cuencos con bases pedestales y jarras con asas aplanadas dentro del estilo Casma (Daggett, 1983; Pozorski \& Pozorski, 2012: table 3, figs. 11 y 13). Melissa Vogel (2011) ha asociado este estilo Casma Inciso con un estado expansivo, con el sitio grande de El Purgatorio en Casma como su capital. Vogel considera que el estilo Casma empezó en el Horizonte Medio y siguió durante el Intermedio Tardío.

Es importante enfatizar que también existen muchas diferencias entre el estilo Casma y la cerámica de Coscopunta, tanto en sus detalles como en la presencia de técnicas, formas de vasija y tipos de adorno como el uso del palateado para formar cerámica, el uso de moldes para producir adorno en bajo relieve, la presencia de cuencos ralladores y la popularidad de pintura blanca (Pozorski \& Pozorski, 2012: table 3, figs. 13, 14, 17, 20). Además, el inventario de decoración plástica sobre cántaros del estilo Casma Inciso incluye combinaciones de incisión, punteados, mecido llano, mecido dentado, impresión dentada, círculos estampados, círculos estampados con puntos centrales, círculos concéntricos, protuberancias aplicadas, bandas aplicadas y adornos zoomórficos. La mayoría de estos no aparece en Coscopunta ni los otros sitios conocidos del Intermedio Tardío en el Callejón de Huaylas.

La cerámica local de Coscopunta tiene más en común con los otros estilos del Callejón de Huaylas y los Conchucos que con el estilo Casma de la costa. Por ejemplo, el estilo Aquilpo de la zona de Marcará y Carhuaz favorece la decoración plástica en el exterior de pequeños cántaros y cuencos. Las técnicas decorativas más comunes son círculos con punteados centrales y muescas incisas pero carece de decoración pintada o engobe (Lau, 2010: 271). Si se acepta la descripción de Aquilpo, indicada anteriormente, la cerámica de Coscopunta está suficientemente diferenciada como para ser considerada un estilo independiente pero relacionado a lo de Aquilpo. Pese a que en la cerámica Coscopunta también predominan los cuencos y pequeños cántaros de alfar oxidado, frecuentemente hay engobe rojo y, en algunos casos, la pintura. Mientras que su decoración más común son los círculos estampados, no hacen uso de muescas incisas. Ya que el estilo Aquilpo fue definido sobre la base de ceramios provenientes del área de Marcará y Carhuaz, sobre las laderas occidentales de la Cordillera Blanca, probablemente no debería sorprender el contraste, dado el emplazamiento de Coscopunta sobre los contrafuertes de la Cordillera Negra. Desafortunadamente, la publicación incompleta del estilo Aquilpo, por Amat y Vescelius, hace imposible una comparación más detallada.

El trabajo de Lau en Chinchawas ofrece una descripción más sistemática de un conjunto del Intermedio Tardío del Callejón de Huaylas (Lau, 2010: 264-269). Chinchawas dista unos $20 \mathrm{~km}$ al norte, pero como en el caso de Coscopunta, 
se ubica en las tierras agrícolas altas de la Cordillera Negra. Lau observa que, comparado con el conjunto de la fase previa (i.e. Warmi), la cerámica Chakwas muestra una declinación sustancial en calidad y diversidad. A diferencia del grupo de Coscopunta, esta estuvo compuesta por vasijas más abiertas que cerradas pero probablemente esto nos dice más acerca del grado de selectividad (o preferencia) en el conjunto Coscopunta antes que una indicación de diferencias estilísticas significativas entre estos dos grupos de cerámica. Chinchawas, como Coscopunta, tiene cuencos simples con paredes cóncavas y el ocasional cuenco con base anular. Chinchawas también muestra cántaros con cuellos cóncavos, algunos de los cuales se parecen a los de Coscopunta. Como en Coscopunta, los diseños pintados son escasos pero cuando aparece el pintado, es sobre cuencos con pigmento negro o bandas verticales rojas sobre el cuello de los cántaros. Así como hay numerosas similitudes, las diferencias entre los conjuntos son, al menos, notables. Los cántaros con asas cintadas parecen ser menos comunes en el conjunto de la fase Chakwas que en Coscopunta y las asas cornisa y borde adornado, comunes en los cuencos Chakwas, no están presentes en Coscopunta. En el conjunto de Chakwas es más común la decoración punteada e incisa sobre asas planas, cuellos de cántaros y exteriores de cuencos y son considerables las variedades y las configuraciones de puntadas e incisiones. Por el contrario, la decoración de las vasijas de Coscopunta está limitada a pequeños círculos estampados en bandas horizontales simples. En Chinchawas, los rasgos decorativos distintivos de la fase cerámica Chakwas consisten en la aplicación de nódulos, adornos y filetes verticales de pastillado. Si bien los nódulos aplicados se dan con frecuencia en Coscopunta, los adornos y filetes están ausentes. Cuando un filete vertical se presenta en Coscopunta (fig. 19), parece fuera de lugar y con un examen más detenido parece pertenecer a una vasija importada. La hipótesis de que este cántaro podría ser importado de la zona de Chinchawas no se basa simplemente en la presencia de filetes porque existen elementos decorativos fileteados en otras partes de Ancash durante el Periodo Intermedio Tardío y Horizonte Tardío (p. ej. el fragmento ilustrado por Wilhelm Diessl [2004: fig. Hua102D] del sitio de Pariac en el distrito de Huantar. El adorno de filetes sobre el cuello de la vasija de Coscopunta se asemeja a los filetes de Chinchawas en su posición (vertical), su ubicación en el cántaro (sobre el parte medio del cuello compuesto) y el pequeño tamaño de los filetes aplicados e incisos con tres a cuatro líneas. En contraste, el «filete» en Pariac aparece sobre un asa encima de la boca de la vasija y el aplicado con incisiones es largo. En este ejemplo, tal como muchos otros casos, el uso de filetes o protuberancias incisas son distintos en forma, tamaño y contexto cuando se compara con los de Chinchawas o el cántaro importado a Coscopunta.

En general, la cerámica local de Chinchawas y Coscopunta tienen similitudes en términos de tecnología, forma de las vasijas y decoración, pero hay suficientes diferencias como para permitir distinguirlas fácilmente, a pesar de la relativa proximidad de los lugares de hallazgo y su presunta contemporaneidad.

Las diferencias observadas entre la cerámica Coscopunta y los estilos del Periodo Intermedio Tardío de Chinchawas y el área de Marcará/Carhuaz, parece resaltar 
un patrón más general de variedad estilística sustancial en la cerámica de la sierra de Ancash durante el Periodo Intermedio Tardío. Este aspecto puede reforzarse aún más a través de una comparación más detallada de las vasijas de dicho período encontradas en las cabeceras del río Santa en la Cordillera Blanca, en los sitios de Aquish Urán y Santo Toribio, por Francisco Bazán (Bazán, 2011). Estas, si bien enfatizan la decoración plástica, tienen muchos rasgos distintivos y son fácilmente distinguibles de las vasijas procedentes de Coscopunta.

Una rápida comparación con el estilo Pójoc de las alturas, en los alrededores de Chavín de Huántar, igualmente muestran fuertes diferencias en forma y decoración. La popularidad de cántaros con cuello compuesto y la decoración con filas de círculos concéntricos estampados, tan populares en Pójoc y Waman Wain (Burger, 1982), están completamente ausentes en la cerámica local de Coscopunta.

Como hemos visto, el estilo de cerámica de la sierra de Ancash durante el Periodo Intermedio Tardío es muy variable y diverso, y no parece haber sido emblemático de grandes unidades étnicas o políticas. Es más probable que pueda reflejar patrones complejos de producción e identidad de comunidades locales. Este panorama es paralelo a las conclusiones de Isabelle Druc (2009) basadas en sus investigaciones etnográficas y etnohistóricas de la producción de cerámica en las sierras de Ancash (Lau, 2010: 243-246; Orsini, 2006). Este patrón se contrasta con algunos estilos de cerámica del Periodo Intermedio Tardío como Casma y Chimú que han sido interpretados frecuentemente como manifestaciones de estados expansivos como el Estado Casma («Casma Polity») y el Reino de Chimor.

El contacto entre comunidades serranas del Periodo Intermedio Tardío en Ancash se refleja en las numerosas similitudes entre los estilos, así como en la presencia ocasional de cerámica exótica. El caso de una vasija procedente de Chinchawas en el conjunto de Coscopunta proporciona evidencia de intercambio entre comunidades vecinas del Callejón de Huaylas y sugiere otra clase de contactos. Finalmente, las semejanzas con el estilo Casma de los valles de Chao y Huarmey y la presencia de una botella importada de la costa norte cuyo estilo se asemeja a la de la cultura Lambayeque o Sicán (fase Sicán Tardío) en la colección de Coscopunta, confirma que durante el Periodo Intermedio Tardío la interacción se extendió más allá de los límites del Callejón de Huaylas, hacia el oeste, hasta la parte baja de los valles costeños.

Como hemos indicado, el contexto original de la cerámica y otros restos descritos aquí no es seguro y debe ser confirmado por excavaciones en el futuro. Sin embargo, las indicaciones ofrecidas por el agricultor quien los recuperó en 1979 sugieren que los objetos fueron enterrados en una chacra en Coscopunta, un lugar ubicado a 3633 msnm cerca del límite superior para la agricultura. Hemos planteado como hipótesis que son ofrendas a un pequeño huanca visible en un campo de cultivo ubicado en el centro de la aldea.

Pero, ipor qué hacer ofrendas a un huanca aislado en el medio de una chacra? El papel de los huancas en el sistema religioso andino no ha sido el enfoque de investigación intensiva a pesar de su amplia distribución en los Andes Centrales. El libro A Culture of Stone: Inka Perspectives on Rock de la historiada de arte 
Carolyn Dean (2010) ha explorado el rol de las piedras sagradas incluyendo los huancas en la cultura Inca, pero como el arqueólogo Victor Falcón Huayta (2004) ha documentado, la existencia de huancas tiene una larga historia anterior a Tawantinsuyu. Esta historia incluye un aparente incremento de la presencia de huancas durante el Periodo Intermedio Tardío en la sierra peruana.

El estudio que más luz ofrece sobre el huanca y posibles ofrendas de Coscopunta es un trabajo realizado por el antropólogo Pierre Duviols (1979) en el cual identifica una tradición de monolitos, conocidos como huancas, colocados por los hombres en el paisaje andino. Su área de dispersión mayor se sitúa entre los 2800 y 4000 msnm. Duviols escribe que la persistencia de un culto actual orientado a los huancas es indudable, y que él mismo ha observado la persistencia de tal culto en relación a los pequeños monolitos plantados en medio de los campos agrícolas. Los huancas descritos por Duviols se asemejan al huanca de Coscopunta mencionado anteriormente. En su artículo, Duviols narra un caso en 1972 donde observó a un agricultor de Tusi, Cerro de Pasco, haciendo ofrendas de coca y tabaco a un huanca ubicado en medio de su campo de cultivo. En base a una revisión amplia de evidencia etnográfica y etnohistórica, Duviols concluye que desde AD 1350 (i.e. Periodo Intermedio Tardío), un culto de huancas se extendía por la mayor parte de la sierra y que piedras no trabajadas, ahora conocidas como huancas, fueron utilizadas para demarcar su posesión de terrenos y para bautizar su nuevo territorio. Una categoría de estos huancas se conoce como marcayoc porque «protege y favorece al campo (chacra) en el que está situado», generalmente «al medio» de la chacra. Según Duviols, el huanca siempre fue masculino y era el doble del ancestro fundador o epónimo en forma petrificada. Algunos huancas fueron especializados en el agua o la tierra. Dada la posición del huanca de Coscopunta en el centro de una de las chacras más ricas de la aldea y su asociación actual con el agua y su circulación, es posible que las ofrendas de comida y bebida contenidas en las vasijas descritas en este artículo fueron enterradas alrededor de este monolito en el Periodo Intermedio Tardío. Tal vez como indica Duviols, la meta fue mantener el abastecimiento suficiente de agua, adecuado sol para prevenir las heladas precoces, enriquecer los cultivos y producir cosechas abundantes. Con ofrendas a los huancas ubicados en las chacras, como es el caso de Coscopunta, se les pide la «buena alimentación (allin micui) para los runa».

\section{Agradecimientos}

Este artículo fue traducido al castellano por nuestro colega y amigo Victor Falcón Huayta, por lo cual estamos muy agradecidos. Queremos agradecer, asimismo, a Francisco Bazán, George Lau, John Verano y Steven Wegner por su ayuda con la investigación y preparación del manuscrito; Izumi Shimada por sus observaciones; Christopher Milan por la preparación del mapa y Julissa Ugarte para su traducción al castellano del estudio sobre huancas de Pierre Duviols. También a los dos revisores anónimos del manuscrito por sus comentarios y sugerencias. 


\section{Referencias citadas}

ANTÓN, S. C., 1989 - Intentional Cranial Vault Deformation and Induced Changes of the Cranial Base and Face. American Journal of Physical Anthropology, 79 (2): 209-253.

BAZÁN, F., 2011 - Asentamientos tardíos del Santo Toribio y del Auquish Urán. In: Arquitectura prehispánica tardía: construcción y poder en los Andes centrales (K. J. Lane \& M. Luján, eds.): 93-121; Lima, Perú: Universidad Católica Sedes Sapientiae, Fondo Editorial UCSS .

BURGER, R. L., 1982 - Pójoc and Waman Wain: Two Early Horizon Villages in the Chavín Heartland. Nawpa Pacha, 20: 3-40.

BUSE, H., 1965 - Introducción al Perú, 389 pp.; Lima: Imprenta del Colegio Militar «Leoncio Prado».

DAGGETT, C., 1983 - Casma Incised Pottery: an Analysis of Collections from the Nepeña Valley. In: Investigations of the Andean Past (D. Sandweiss, ed.): 209-225; Ithaca: Latin American Studies Progress, Cornell University.

DEAN, C., 2010 - A Culture of Stone: Perspectives on Rock, 325 pp.; Durham: Duke University Press.

DIESSL, W., 2004 - Sitios arqueológicos en la sierra de Ancash: Huántar, San Marcos, Chavín, 582 pp.; Trujillo: Instituto Cultural Runa.

DONNAN, C., 1990 - An Assessment of the Validity of the Naymlap Dynasty. In: The Northern Dynasties Kingship and Statecraft in Chimor (M. E. Moseley \& A. CordyCollins, eds.): 275-296; Washington D. C.: Dumbarton Oaks Research and Collection.

DRUC, I., 2009 - Tradiciones alfareras, identidad social y el concepto de etnias tardías en Conchucos, Ancash, Perú. Bulletin de I'Institut d'Études Andines, 38 (1): 87-106.

DUVIOLS, P., 1979 - Un symbolisme de l'aménagement et de l'exploitation de l'espace. Le monolithe «huanca» et sa fonction dans les Andes préhispaniques. L'Homme, avril-juin XIX (2): 7-31.

FALCÓN HUAYTA, V., 2004 - Los Orígenes del Huanca como Objeto de Culto en la Epoca Precolonial. Allpanchis, 64: 35-58; Cusco.

IMBELLONI, J., 1933 - Los Pueblos Deformadores de los Andes. La Deformación Intencional de la Cabeza como Arte y Como Elemento Diagnóstico de las Culturas. Anales del Museo Argentino de Ciencias Naturales, 37 (75): 209-253.

LANNING, E., 1965 - Current research: highland South America. American Antiquity, 31 (2): 139-140.

LAU, G. F., 2010 - Ancient Community and Economy at Chinchawás (Ancash, Peru), $x+404$ pp.; New Haven: Yale University.

MARTÍNEZ, C., 1986 - Cerámica prehispánica norperuana. Estudio de la cerámica Chimú de la colección del Museo de América de Madrid, 487 pp.; Oxford: BAR International Series 323.

ORSINI, C., 2006 - Metáforas de complejidad social? Huari, Llacuaz, organización del territorio y especialización económica a Chacas (Valle de Chacapata, Perú). In: La Complejidad Social en la Sierra de Ancash: ensayos sobre paisaje, economía, y continuidades culturales (A. Herrera, C. Orsini \& K. Lane, eds.): 151-164; Milán: Civiche Raccolte d'Arte Applicata del Castello Sforzesco-Raccolte Extraeuropee. 
POZORSKI, S. \& POZORSKI, T., 2012 - Exploring access control at Taukachi Tardío: a Late Casma culture site within the Casma Valley of Peru. Nawpa Pacha, 32 (2): 207-230.

SHIMADA, I., 1990 - Cultural continuities and discontinuities on the northern north coast of Peru, Middle-Late Horizons. In: The Northern Dynasties Kingship and Statecraft in Chimor (M. E. Moseley \& A. Cordy-Collins, eds.): 297-392; Washington D. C.: Dumbarton Oaks Research and Collection.

SHIMADA, I. \& ONO, M. (eds.), 1994 - Excavations at the Ancient Golden Capital, Sicán (en japonés), 400 pp.; Tokio: Asahi Shinbun.

VOGEL, M., 2011 - Style and interregional interaction: ceramics from the Casma capital of El Purgatorio. Nawpa Pacha, 31 (2): 201-224. 
Anexo 1 - Datos adicionales sobre la cerámica de Coscopunta

\begin{tabular}{|c|c|c|c|c|}
\hline Forma & Figura & Alto $(\mathbf{c m})$ & $\begin{array}{c}\text { Diámetro de la } \\
\text { boca }(\mathbf{c m})\end{array}$ & Dureza (Mohs) \\
\hline Cuenco 1 & 7 & 6,7 & 13,4 & $2 / 3$ \\
\hline Cuenco 2 & 8 & 6,2 & 14,0 & $3 / 4$ \\
\hline Cuenco 3 & 9 & 3,0 & 8,7 & $4 / 5$ \\
\hline Cuenco 4 & 10 & 3,5 & 9,1 & $2 / 3$ \\
\hline Cántaro 1 & 14 & 19,0 & 8,7 & $2 / 3$ \\
\hline Cántaro 2 & 16 & 18,3 & 6,2 & $2 / 3$ \\
\hline Cántaro 3 & 18 & 19,5 & 7,5 & $3 / 4$ \\
\hline Cántaro 5 & 20 & 7,4 & 4,2 & $5 / 6$ \\
\hline Cántaro 5 & 21 & 9,4 & 5,5 & $5 / 6$ \\
\hline Cántaro 6 & 22 & 9,7 & 5,9 & $3 / 4$ \\
\hline Cántaro 7 & 23 & 8,2 & 6,7 & $3 / 4$ \\
\hline Cántaro 8 & 24 & 8,0 & 5,9 & $3 / 4$ \\
\hline Cantaro 8 & 25 & 10,0 & 5,7 & $5 / 6$ \\
\hline Cántaro 9 & 26 & 7,5 & 6,6 & $3 / 4$ \\
\hline
\end{tabular}

